www.sciforum.net/conference/ecea-1

Conference Proceedings Paper - Entropy

\title{
An Open Logic Approach to EPM
}

\section{Rodolfo A. Fiorini ${ }^{1, *}$ and Piero De Giacomo ${ }^{2}$}

1 Politecnico di Milano, Department of Electronics, Information and Bioengineering, Milano, Italy; EMail: rodolfo.fiorini@polimi.it

2 Dept. of Neurological and Psychiatric Sciences, Univ of Bari, Italy; E-Mail: piero.degiacomo@tin.it

* E-Mail: rodolfo.fiorini@polimi.it;

Tel.: +039-02-2399-3350; Fax: +039-02-2399-3360.

Received: 11 September 2014 / Accepted: 21 October 2014 / Published: 3 November 2014

\begin{abstract}
EPM is a high operative and didactic versatile tool and new application areas are envisaged continuosly. In turn, this new awareness has allowed to enlarge our panorama for neurocognitive system behaviour understanding, and to develop information conservation and regeneration systems in a numeric self-reflexive/reflective evolutive reference framework. Unfortunately, a logically closed model cannot cope with ontological uncertainty by itself; it needs a complementary logical aperture operational support extension. To achieve this goal, it is possible to use two coupled irreducible information management subsystems, based on the following ideal coupled irreducible asymptotic dichotomy: "Information Reliable Predictability" and "Information Reliable Unpredictability" subsystems. To behave realistically, overall system must guarantee both Logical Closure and Logical Aperture, both fed by environmental "noise" (better... from what human beings call "noise"). So, a natural operating point can emerge as a new Trans-disciplinary Reality Level, out of the Interaction of Two Complementary Irreducible Information Management Subsystems within their environment. In this way, it is possible to extend the traditional EPM approach in order to profit by both classic EPM intrinsic Self-Reflexive Functional Logical Closure and new numeric CICT Self-Reflective Functional Logical Aperture. EPM can be thought as a reliable starting subsystem to initialize a process of continuous self-organizing and self-logic learning refinement.
\end{abstract}

Keywords: EPM; machine learning; system theory; elementary pragmatic model; cybernetics; general systems theory.

\section{PACS Codes: ....}




\section{Introduction}

Automatic vs. controlled, convergent vs. divergent, implicit vs. explicit, reflexive vs. reflective, etc. processing correspond to theoretical cognitive dichotomies that have been around for a few generation and have contributed to the development of many neurocognitive models and systems in the past century. Among them, the Elementary Pragmatic Model (EPM) was developed by Piero De Giacomo in the 1970s [1-3], following Gregory Bateson's constructivist participant observer concept in the "second order cybernetics, [4], to arrive to what was called "new cybernetics," according to cybernetics classical historical categorization. Initially EPM was used as a theoretical family therapy model to classify the outcomes of dyadic interactions in psychology. It was used successfully by a group of therapists in family therapy and in clinical psychiatric training and applications (e.g. schizophrenia, nervous anorexia, etc.) Later it was applied to develop interactive psychotherapic strategies, online counseling and E-therapy. Since the beginning of the new millennium its application area has been extended to other disciplines and even to engineering applications like user modeling, constraint requirements elicitation, software creativity and adaptive system design and development [5-9]. EPM has shown to be a high operative and versatile tool and new application areas are envisaged continuously [10]. Quite recently, the EPM intrinsic Self-Reflexive Functional Logical Closure contributed to find an original solution to the dreadful double-bind problem in classic information and algorithmic theory (i.e. our contemporary systemic tools and classic information computational and communication algorithms are totally unable to discriminate the difference between an optimal encoded information-rich message and a random jumble of signs that we call "noise" usually) [10,11]. In turn, this new awareness has allowed to enlarge our panorama for neurocognitive system behaviour understanding, and to develop information conservation and regeneration systems in a numeric selfreflexive/reflective evolutive reference framework [10]. Accordingly, new methods and models to build effective applications and strategies, from new forms of inter- and trans-disciplinarity, can be conceived conveniently. Current biomedical cybernetics operative knowledge has reached "fourth order cybernetics" level, where multiple realities can emerge by the freedom of choice of the creative observer that determines the outcome for both the system and the observer [12]. This puts demands on the self-awareness of the observer, and "response-ability" for/in action. If we like to be able to model that kind of behaviour, a logically closed model cannot cope with ontological uncertainty effectively, so EPM needs a complementary logical aperture operational support extension. In fact, EPM provides us with a reliable self-reflexive closed logic starting scheme to face "unknown known" situations $[12,13]$. If we like to use it on more and more complex applications with ability to capture natural emergent phenomena dynamics, we need to extend it to face even unpredictable perturbation ("unknown unknown") [12,13] at system design level. In this case, an evolutive framework to manage unespected dynamics is needed to EPM. In this paper, we present our basic considerations to get an effective reference mind model to reach our goal, starting from a mankind worldview to arrive to a convenient ontological uncertainty management solution, which the final EPM extension can be designed from. As a matter of fact, we apply to EPM the computational information conservation theory (CICT) anticipatory learning system (ALS) approach [14]. To cope with ontological uncertainty effectively at system level, it is possible to use two coupled irreducible information management subsystems, based on the following ideal coupled irreducible asymptotic dichotomy: Information 
Reliable Predictability and Information Reliable Unpredictability. In this way, to behave realistically, overall system must guarantee both Logical Closure (Reactive Information Management, "to learn and prosper") and Logical Aperture (Proactive Information Management, "to survive and grow"), both fed by environmental "noise" (better... from what human beings call "noise") [10]. So, a natural operating point can emerge as a new Trans-disciplinary Reality Level, out of the Interaction of Two Complementary Irreducible Information Management Subsystems. Building on this idea, it is possible to envisage an EPM framework able to profit by both classic EPM intrinsic Self-Reflexive Functional Logical Closure and new CICT numeric Self-Reflective Functional Logical Aperture. In this evolutive framework, classic EPM can be thought as a reliable starting subsystem to initialize a process of continuous self-organizing and self-logic learning system refinement.

\section{Mankind Worldview}

The real world is about incompleteness: incompleteness of understanding, representation, information, etc., what one does when one does not know what's going on, or when there is a non-zero chance of not knowing what's going on. It is based on focus on the unknown, not the production of mathematical certainties based on weak assumptions. Rather it is much better to measure the robustness of the exposure to the unknown, which can be done mathematically through metamodel (a model that examines the effectiveness and reliability of the model), what we call metaprobability, even if the meta-approach to the model is not strictly probabilistic. So, mankind's best conceivable worldview is at most a partial picture of the world, a picture centered on man. We inevitably see the universe from a human point of view and communicate in terms shaped by the exigencies of human life. However multifarious its make-up, there is a general agreement about the character of the world representation shared by human beeings and the way it is ordered. Explanations of particular phenomena differ from one person to another, but without basic concurrence as to be the nature of things, there would be neither science nor common sense, agreement nor argument. The most fundamental attributes of our shared view of the world are confined, moreover, to sane, hale, sentient adults. To see the world more or less as others see it, one must above all grow up and to be quite healthy, in a wellness state; the very young, like the very ill, are unable to discern adequately what is themselves and what is not. Because we cherish the past as a collective guide to behavior, the general consensus alters very slowly. Scientists as well as laymen ignore evidence incompatible with their preconceptions. New theories which fail to fit established views are resisted, in the hope that they will prove false or irrelevant; old ones yield to convenience rather than to evidence. That, in turn, invites a corresponding acknowledgement of the power of science. Imperfect though it may be, it is the best means we have to understand ourselves and the world. According to the anthropocentric character of the worldview of American-born British geographer and historian David Lowenthal (1923-) [15], the perceptual powers and central nervous systems of many species are qualitatively, as well as quantitatively, different from man's. Men can observe, but never experience, the role of surface tension and molecular forces in the lives of small vertebrates, the ability of the octopus to discriminate tactile impressions of taste, of the butterfly to sense forms through smell, or of the jellyfish to change its size and shape. The tempo of all varieties of experience is also specific. Time yields humans on the average eighteen separate impressions, or instants, every second; images presented more rapidly seem to fuse 
into continuous motion, But there are slow-motion fish that perceive separate impressions up to thirty each second, and snails to which a stick that vibrates more than four times a second appear to be at rest. As with time, so with space; humans do perceive, structure and share one of many possible world models, more Hyperbolic than Euclidean structured.[16-18] The six cardinal directions are not equivalent for us: up and down, front and back, left and right have particular values because we happen to be a special kind of bilaterally symmetrical terrestrial animal... Other species apperceive quite differently. Even the fact that physical space seems to us three dimensional is partly contingent on our semicircular canals, on our size, and on the shape of our bodies (an asymmetrical torus); the world of certain birds is effectively two-dimensional, and some creatures apprehend one dimension only [1921]. Man's experienced world model is, then, only one tree of the forest. The difference between this and the others is that man knows his tree is not the only one; and yet can imagine what the forest as a whole might be like. Memory and technology extend our images far beyond the bounds of direct sensation; consciousness of self, of time, of relationship, and of causality overcome the separateness of individual experiences [22-24]. Thanks to what has been likened to "a consummate piece of combinatorial mathematics" [25], we share the conception of a common world model. Whatever the defects of the general consensus, the shared worldview is essentially well-founded. "We are quite willing to admit that there may be errors of detail in this knowledge, " as British philosopher, logician, mathematician, Bertrand Arthur William Russell (1872-1970) wrote [26], referring to science, "but we believe them to be discoverable and corrigible by the methods which have given rise to our beliefs, and we do not, as practical men, entertain for a moment the hypothesis that the whole edifice may be built on insecure foundations" [26]. Human visual space is Euclidean only locally; for normal observers with binocular vision, space has a constant negative curvature corresponding with the Hyperbolic Geometry of Lobacevski, Bolyai and Riemann. But under "optimal conditions", American psychologist James Jerome Gibson (1904-1979) maintains later [17], perceptual space is Euclidean perceived. That is true in the human near-field (Hall's distance up to about cm. 46 in the average). Nevertheless humans show sigmoid neurosensory characteristics and logit neuromotory characteristics by a psychophysics point of view, revealing their basic surviving neurointerface to a hyperbolic structured environment [27]. In 1945-47, highly talented mathematician Rudolf Karl Luneburg (1903-1949) worked out an analysis of the geometry of human visual space as expected from physiognomy and the assumption that the angle of vergence provides a constant measure of distance. From these premises he concluded that human visual space field is hyperbolic [18]. Hyperbolic Geometry is precisely projective relativistic geometry. This is a fundamental understanding [28]. So, in total agreement to Luneburg results, we claim that the detailed human perception experience is Hyperbolic Geometry based. More precisely, external world real system physical manifestation properties and related human perception are Hyperbolic Geometry representation based, while Euclidean approximated locally in the near-field [17]. Furthermore, the fundamental play of human information observation interaction with an external world representation is related by the different manifestation and representation properties of a unique fundamental computational information structuring principle: the Kelvin Transform (KT) of Thomson as key to efficient information representation, structuring external space information to an internal representation and vice-versa by inversive geometry $[29,30]$. 


\section{An Ontology of the Unknown}

Although there are many sources of uncertainty, two basic areas of uncertainty that are fundamentally different from each other were recognized as traditional reference knowledge: natural and epistemic uncertainty. Intrinsic randomness of a phenomenon (e.g. throwing a dice) or natural uncertainty cannot be reduced by the collection of additional data and it stems from variability of the underlying stochastic process. On the other end, epistemic uncertainty results from incomplete knowledge (or lack of information) about the process under study. Unlike natural uncertainty, epistemic uncertainty can be reduced by the collection of additional data. Statistical and applied probabilistic theory is the core of traditional scientific knowledge; it is the logic of "Science 1.0"; it is the traditional instrument of risk-taking. Epistemic uncertainty sources can be reconducted to three main core conceptual areas: a) Entropy Generation (Clausius-Boltzmann), b) Heisenberg Uncertainty Principle and c) Gödel Incompleteness Theorems. A further detailed description of epistemic uncertainty core conceptual areas far exceeds the size of present paper and the interested reader is referred to the extensive bibliography available elsewhere. Epistemic uncertainty sources are treated with the traditional approach of risk analysis, which provides an acceptable cost/benefit ratio to producer/manufacturer, but in some cases it may not represent an optimal solution to end user/customer/consumer. In fact, deep epistemic limitations reside in some parts of the areas covered in decision making. These limitations are twofold: philosophical (mathematical) and empirical (human known epistemic biases). The philosophical problem is about the decrease in knowledge when it comes to rare events as these are not visible in past samples and therefore require a strong a priori, or an extrapolating theory; accordingly predictions of events depend more and more on theories when their probability is small. We can talk about system knowledge uncertainty by referring to "Application" and to "Domain", according to the four-quadrant scheme of Figure 1 [31].

Figure 1. The fourth quadrant of knowledge. The South-East area (in orange) is where Statistics and models fail us [31].

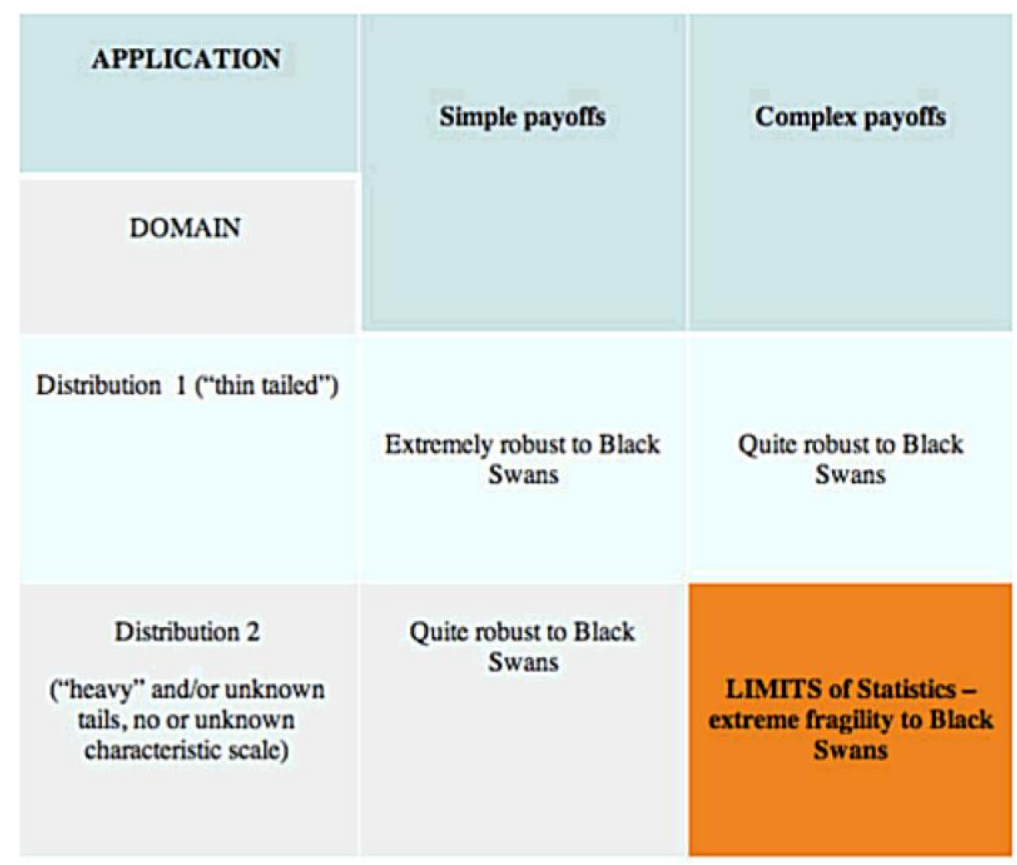


Decision theory, based on a "fixed universe" or a model of possible outcomes, ignores and minimizes the effect of events that are "outside model" or unexpected perturbations. A fixed model considers the "known unknowns" (North-East-quadrant), but ignores the "unknown unknowns" (SouthEast-quadrant).[32-34] The idea of known and unknown unknowns recognizes that the information those in positions of responsibility in government, as well as in other human endeavors, have at their disposal is almost always incomplete. It emphasizes the importance of intellectual humility, a valuable attribute in decision making and in formulating strategy. It is difficult to accept, to know that there may be important unknowns. The best strategists try to imagine and consider the possible, even if it seems unlikely. They are then more likely to be prepared and agile enough to adjust course if and when new and surprising information requires it, when things that were previously unknown become known [34]. So, we have even to think about uncertainty in the characterisation of uncertainty by counterfactual thinking. Counterfactual thinking is exactly as it states: "counter to the facts" [35]. These thoughts consist of the "What if?" and the "If I had only..." that occur when thinking of how things could have turned out differently. Counterfactual thoughts are things that could never possibly happen in reality, because they solely pertain to events that have occurred in the past [35]. In the fourth quadrant of Figure 2, knowledge is both uncertain and consequences are large, requiring more system robustness and resilience [31]. In fact, for instance, can we understand health without considering wild diseases and epidemics? Indeed the normal is often irrelevant. Almost everything in social life is produced by rare but consequential shocks and jumps. All the while almost everything studied about social life focuses on the "normal," particularly with "bell curve" methods of inference that tell you close to nothing about natural events. Why? Because the bell curve ignores large deviations, cannot handle them, yet makes us confident that we have tamed uncertainty. Traditionally, uncertainties are characterized as epistemic, if the model developer sees a possibility to reduce them by gathering more data or by refining models. Uncertainties are categorized as aleatory if the modeler does not foresee the possibility of reducing them. From a pragmatic standpoint, it is useful to categorize the uncertainties within a model, since it then becomes clear as to which uncertainties have the potential of being reduced. Influences of the two types of uncertainties in reliability assessment, codified design, performance-based engineering and risk-based decision-making are always present. More importantly, epistemic uncertainties may introduce dependence between events, which may not be properly noted if their character is not correctly modeled. More generally, decision theory, based on a "fixed universe" or a model of possible outcomes, ignores and minimizes the effect of events that are "outside model". In fact, human made systems can be quite fragile to unexpected perturbation because Statistics can fool you unfortunately [36]. While the advantage of differentiating between natural (aleatoric) and epistemic uncertainty in analysis is clear, the necessity of distinguishing between them is not, by an operative point of view: as a matter of fact, epistemic and aleatory uncertainties are fixed neither in space nor in time. What is aleatory uncertainty in one model can be epistemic uncertainty in another model, at least in part. And what appears to be aleatory uncertainty at the present time may be cast, at least in part, into epistemic uncertainty at a later date [37]. It is much better to consider ontological uncertainty [38] as an emergent phenomenon out of a complex system [14]. All the while almost everything, classically approached and traditionally studied, about social life focuses on the "normal," particularly with "bell curve" methods of inference that tell you close to nothing about natural events. 
Why? Epistemic uncertainty sources are still treated with the traditional approach of risk analysis only, which provides an acceptable cost/benefit ratio to producer/manufacturer, but in some cases it may not represent an optimal solution to end user [10]. In fact, deep epistemic limitations reside in some parts of the areas covered in decision making. In fact, the bell curve ignores large deviations, cannot handle them, yet makes us confident that we have tamed uncertainty [39]. On the other end, almost everything in social life is produced by rare but consequential shocks and jumps. As the experiences of the 1970s, 1980s, 1990s and 2000s have shown, unpredictable changes can be very disorienting at enterprise level. These major changes, usually discontinuities referred to as fractures in the environment rather than trends, will largely determine the long-term future of organization. They need to be handled, as opportunities, as positively as possible.

\section{Human Eulogic Thought and Communication}

Rational human thinking is like a solid archipelago emerging out of an ocean of unaware intuitions. Human brain is an harmonization machine fed by unaware intuitions to produce learning and rational awareness about our environment. Our "Eulogic Thought" emerges out of a continuous harmonization interaction between Paleologic and Neologic Thought components. "Emotional Intelligence" (EI) and "Emotional Creativity" (EC) [40] coexist at the same time with "Rational Thinking," sharing the same input environment information. Different forms of knowledge representations inducing a nondeductive procedure during inferences exist. For instance, the metaphor is a representation modality that bypasses deductive procedure. The source of the metaphor brings a structure exhibiting explicit and implicit attributes of the target. The metaphor allows direct inferences and learning about new things (target) by extending what it is already known about the source [41-43]. Similarly, the process of hierarchical inheritance in semantics networks allows direct inferences on properties shared by classes, subclasses and instances of objects without effort of explicit deduction [44]. Another form of direct inference is heuristics that take advantage of specialised knowledge to permit inferential short-cuts $[45,46]$. Mental imagery also provides with detailed representation of objects that conveys implicit information without deductive effort [47]. In logic, diagrammatic notation is the main form of knowledge representation that excludes a deductive procedure through the process of spatial inference. To reach a clear understanding of the basic interplay between neologic and paleologic, conscious and unconscious mind components at personal and social level, the triad subjective worldview-shared worldview-human communication can be of great help. In the following section reference basic concepts of their interplay is presented.

\subsection{Subjective Worldview}

The relationship between the subjective consciousness and the outer world representation is possibly the most important scientific and philosophical problem at the present time. The science of cognition, which strives to clarify this relationship, is situated at a cross roads between the humanistic and the natural sciences, represented mainly by Western philosophy and psychology on the one hand and by neuroscience and biology on the other hand. Within this field several researcher admit a lack of systematic experience based investigations of the subjective perceiving consciousness. There exists an inwardly focussed awareness of any given outwardly focussed mental state, regardless whether this 
state is a mentally constructed state (which includes mental events, inferential valid cognition as well as mistaken cognition) or it is a non-constructed or non-conceptual state (this includes the main minds, sense direct valid cognition and mental direct valid cognition).

\subsubsection{Eastern and Western Experiences}

What the self-reflexive awareness does is that it experiences the relative mental events in a nonconceptual direct manner. This makes it potentially well suited to function as a neutral observation tool in the context of a systematic study of consciousness. As an example, Tibetan Buddhism employs consciousness training in the form of so called analytical meditation in order to strengthen this self reflexive observing consciousness. This makes the individual capable of observing their own mind as if it was an impersonal object. This can be useful if one wishes to distance oneself from destructive emotional imbalances or if one wishes to observe ones own mental fixations in a relative perspective. This process functions at the same time, as a method for seeing through the so called "I", and, as maintained by some, finally our self-reflexive awareness is that which is capable of experiencing the ultimate luminous quality of mind. Perhaps some people will argue that it is pathological to intentionally split the mind into two parts, but Buddhism maintains that if this is done correctly, then the mind can be liberated from its identification with negative and destructive thought patterns. The theory is that when we stop identifying with a given emotion or a given point of view, the energy that was bound in that conditioned structure, that upholds the idea of an "I", will be released. This energy flows instead into the observing part of the consciousness. Thereby the evolution of consciousness is strengthened, since the self reflexive observing awareness connects to higher and more subtle layers of consciousness. This strategy might be a useful device if we wish to develop a systematic research tool that actually has first person access to the mind. We may note that the closest parallel to the selfreflexive observing consciousness, namely the so called "auto-noetic cognition" or "meta-cognition" described by modern neuro-scientists, represents the highest evolution of consciousness, apparently limited to "homo sapiens." It is developed based on the latest developed neural networks, interpreted by the individual as an "I" $[48,49]$. However, while this auto-noetic cognition in modern science is regarded as a result of the sense of an "I", the Buddhist science of consciousness goes one step further and trains the self reflexive awareness to potentially transcend the limitation that the sense of an "I" represents. Thereby perspectives which extend beyond the normally known functions of consciousness are reached. This is how enlightened consciousness is developed and said to culminate in the state of "Buddha hood."

On the Western side, Chilean psychiatrist and psychoanalyst Ignacio Matte Blanco (1908-1995) devoted many years of his work in developing a rule-based structure for the unconscious which allows us to make sense of the non-logical aspects of thought [50]. According to Matte Blanco, the fundamental principles of the unconscious are the "generalization principle" and the "symmetric principle," through which it carries out the primary process (whereas the secondary process concerns the "modus operandi" of conscious thought). Subsequently, through them, Matte Blanco tries to explain the previous Freudian characteristic principles of unconscious. In particular, he re-examines the classical Freudian agencies (or instances) in the light of his principles. The conscious and unconscious are two different modes of being respect to the psychophysics unity of the Man, asymmetric and in 
becoming the first, symmetric and static the second: this terminology is due to the fact that the latter is regulated by the above mentioned symmetric principle, differently to the first. The symmetry and staticity, characterizing the unconscious, do not allow any finite-dimensional space-time idea and any sequential logic reasoning (which relies on asymmetry), so that the asymmetric conscious thought seems to be the result of a sort of "symmetry breaking" of the symmetric unconscious world (recalling besides as the symmetry breaking mechanisms, according to the Modern Physics, are at the basis of any fundamental physical phenomenology from the dynamical viewpoint). The symmetric thought is unthinkable without the asymmetric one, and the limit between normality and abnormality is given by the degree of reciprocal compenetration of these two modes of being. The Matte Blanco's notion of unconscious as infinite set resumes the distinction between set and class, typical of formal set theory. The unconscious does not distinguish between partial and total object and, moreover, each element of any set is conceived as having only human qualities (anthropomorphization). This last property is a fundamental epistemological assumption common to many theory of the history of human thought, even if Matte Blanco deduced it from psychiatric and psychoanalytic considerations. The notion of infinite set in Mathematics, analogically compared with the symmetric mode of being of the unconscious, precisely with its property of indistinguishability between the part and the whole, in the sense that they both have the same cardinality, is just the first notion of infinite set. Again according to Matte Blanco, many other mathematical concepts (like that of limit process) have their origins by the attempts to asymmetrically explain the properties of the symmetric one. Every normal psychic state varies within an interval (or range) including a right mixing of both these modes, but whose ratio is continuously changing. Moreover, if we consider, for instance, a mathematical study, hence a full asymmetric thought, at least in theoretical principle and at the end of his formulation, then there is always an unavoidable emotional involvement which may be described as an involvement of asymmetrical type. Therefore, albeit a certain human result, like a mathematical proof, may seem to be the result of a completely asymmetrical work, indeed its production is never separated from an emotive-affective component of symmetric nature. This last remark is fundamental for understanding the nature of a creative thought. Indeed, a creative thought is just of this last type, that is to say, it is the result of a dialectical (inseparable) interaction of the two modes of the being, symmetric and asymmetric. Further, according to Matte Blanco, the consciousness may think only in a threedimensionally way, plus eventually a fourth temporal dimension, so that the three-dimensional space seems to be the dimension of consciousness and imagination. The human thought thinks mainly by three-dimensional images, also abstract (confirming a suggestion by J. Hadamard [50]). On the other hand, some consciousness contents are available only by means of the introspection, which is an asymmetric phenomenon. According to Matte Blanco, it has a precise characteristic: namely, it never concern the instant in which takes place the introspection, but it concerns the immediately previous moments (hence, the past). The human thought exists only if it is reflected on itself, or else, the most peculiar character of the human thought is just this reflectivity. The elusive character of the conscious thought is due to the fact that the real nature of the consciousness is temporally located between these two modes of being, that symmetric and the asymmetric one, so that each time we try to think a conscious content, then we diachronically restrict ourselves to the asymmetric mode, so completely excluding the (synchronically inevitable) symmetric components. Only historically thinking it is 
possible to avoid (or minimize) the latter. The concept of emotion plays a fundamental role for all the psychic life, above all in the formation of thought. It is also describable by means of introspection. Nevertheless, it is mainly (but not completely) a symmetric phenomenon [50]. This phenomenon can be identified in many historical cases of fundamental creative innovation: for instance, the celebrated Einstein's (as well as the main Riemannian) ideas on space-time, have been mainly based, at least in their initial theoretical stance, on a given philosophical ideas, hence with a significant sentimental (hence emotive, according to neuroscientist Antonio R. Damasio [51,52]) participation. In this regards, one of the most paradigmatic example is given by the proof of Poincaré conjecture by Russian mathematician Grigorij J. Perelman, who has outlined it in three papers only, without many formal details between 2002 and 2003. Later, experts found that these papers contained all the ideas need for constructing a complete proof of this geometrisation conjecture. For the relative shared validation, it has been necessary to explicitly deduce any elementary logical passage $\mathrm{EP}_{\mathrm{i}} \Rightarrow \mathrm{EP}_{(\mathrm{i}+1)}$ involved in it, reaching a complete proof written in several hundred pages (more than six hundred [53]), whilst Perelman achieved it with a few ones in an utter and inexplicable (if not at the intuitive level) creative manner. This is an epitome of the mathematical creative work.

One of most important Matte Blanco notion is that any human psychic manifestation is the result of the interactions and/or cooperations between these two modes of being. And this implies that any human reasoning is the result of the combination of the rules of two logic, that symmetric and the bivalent (or asymmetric) one, which, in turn, are interpreted as components of a unique bilogic. Therefore, every human psychic phenomenon turns out to be a bilogic process which is a chain of symmetric and asymmetric subprocesses whose combination modes are, a priori, various and infinities, giving rise to the rich variety of the human thoughts. The emergence at the threshold of consciousness of a bilogic process is related with the concept of "triad" by Matte Blanco. This last concept should be meant as a fundamental structure of the Mathematical Logic, according to which it is the entity formed by two theoretical objects related each other by a third object called "relation." Matte Blanco thinks that the logic-mathematical structures are the results of the applications of his theory of human psyche structure based on the notion of bilogic process. Considering, for example, an arbitrary insight process, it is therefore plausible to think that the long unconscious work in finding a proof (mentioned, amongst others, by J. Hadamard [54] and H.J. Poincaré [55]) is due to the (indivisible and homogeneous unity or) syncretic character of unconscious which has mainly an immediate unifying and multiple logic character, impossible to the asymmetric (or conscious) thought. Indeed, following what mentioned in [55], according to Poincaré, the most insights obtain an unexpected inner decisive inspiration often in a moment in which the mind is very far from the problem under examination which has been, for a long time, inconclusively discussed. It is as if, all the elements of the searched solution, put in movement from the previous study (of the problem under examination), continue to mechanically roam within a sort of "cerebral maze" until when, suddenly, they finally find a road along which link themselves, in a continuous chain (that is, a derivation), from the hypotheses towards the thesis. Afterwards, Hadamard says as, amongst the infinite possible choices (namely, the above road), that is to say, amongst the infinite possible association of ideas (which pursue the solution), our own unconscious seems to choose the one satisfying a kind of "beauty criterion" (as P.A.M. Dirac noted first [56,57]) which is ruled by a certain instinctive sense of scientific-artistic elegance. In turn, the latter is influenced by our 
scientific education [58], that is to say, it is just the method that will become an instinct, in a manner that is impossible to explain with words. Maybe, this might be related to the continuous content exchange between explicit and implicit memories. On the other hand, taking into account what just said by Poincaré and Hadamard, Mario Ageno [58] adds that only the method however cannot open the way to find the solution of a problem if one does not learn to discover new problems and to correctly formulate them too. Hence, the Matte Blanco bilogic process may be considered as one of the most suitable candidate in trying to explain a creative process, whence it follows the unescapable role (or influence) played by unconscious (or symmetric) thought in finding a new mathematical proof (which is not otherwise rationally deducible, for instance, by means of generalization, analogy, extension, reductio ad absurdum, etc ), specially as concerns the affective-emotive aspects involved in it. The unavoidable presence of symmetric thought aspects also explains why, in certain cases, the new proof of a theorem is almost never perfect in its first initial form, but it shall reach its perfect and correct (in a certain sense, definitive) form after the subsequent correction made on some initial imperfections, that is, by elimination of any symmetric thought interference. The brain perceives and works out the reality simultaneously by means of both processes and they are continuously in reciprocal communication through bidirectional connections and continuous referential links. The thought by images is the primary (but not the unique) and specific expression of complex emotions like desires, beliefs, expectations and other holistic sensorimotor experienced, representational and mathematical contents and others, which cannot be verbally expressed. Thus, asymmetrical thoughts are at the surface while the symmetrical relations make up multiple lower strata that go deeper until an "invisible mode" or total symmetry is reached. In the deeper, completely unconscious levels, a statement such as "Judy is the mother of Diane" is equally valid as "Diane is the mother of Judy." This statement reversal sounds preposterous to logical, asymmetrical, conscious thought, but the depth of the unconscious has its own rules. There, such a statement is true and incontestable. In this way, the principle of symmetry changes the asymmetrical to symmetrical or, put another way, the logical into the illogical [59].

\subsubsection{A Few Neurophysiological Components}

All the previous conceptual considerations seem to find a solid neurophysiological correspondence into a few fundamental brain sub networks and among them two are specific to our interest. The first one focused on emotions and memory and the second one thought to be involved in the cortical control of emotion. The former is the LeDoux pre-cognitive circuit (a path Thalamus-Amigdala), described by neuroscientist Joseph E. LeDoux (1949-) [60,61] as a neural pathway, subset of the dated Papez cognitive circuit [62]. LeDoux's research interests are mainly focused on the neurophysiology underpinnings of memory and emotion, especially the mechanisms of fear. Ledoux goes on to distinguish the pursuit of his studies from traditional mind-body philosophical inquiry, citing that the self is the totality of the organism which includes conscious and unconscious aspects of the mind. Traditional philosophy of mind concerns itself with the relationship between consciousness and the brain, and Ledoux believes this leaves out an integral portion of brain processes that are unconscious yet essential to formulating the self [62]. The latter is the Papez cognitive circuit (Thalamus, Neocortex, Amigdala, T-N-A) as a neural pathway in the brain first described by American neuroanatomist James Papez (1883-1958) in 1937 [63]. The Papez cognitive-circuit involves various 
structures of the brain. It begins and ends with the hippocampus (or the hippocampal formation). Fiber dissection indicates that the average size of the circuit is about 350 millimeters. The Papez circuit goes through the following neural pathway [64]:

hippocampal formation (subiculum) $\rightarrow$ fornix $\rightarrow$ mammillary bodies $\rightarrow$ mammillothalamic tract $\rightarrow$ anterior thalamic nucleus $\rightarrow$ cingulum $\rightarrow$ entorhinal cortex $\rightarrow$ hippocampal formation.

Papez hypothesized that the hippocampus, the cingulate gyrus (Broca's callosal lobe), the hypothalamus, the anterior thalamic nuclei, and the interconnections among these structures constituted a harmonious mechanism which elaborate the functions of emotions. Recent studies show that it has a more significant role in memory functions than in emotions. The Papez circuit was later modified by American neuroscientist and physician Paul D. MacLean (1913-2007) and known as the "medial limbic" circuit. MacLean's evolutionary "triune brain theory" proposed that the human brain was in reality three brains in one: the reptilian complex, the limbic system, and the neocortex [65]. Although the term "limbic" only originated in the 1940s, some neuroscientists, including Joseph LeDoux, have suggested that the concept of a functionally unified limbic system should be abandoned as obsolete because it is grounded mainly in historical concepts of brain anatomy that are no longer accepted as accurate [62]. Nevertheless, many current international neurologists, like Rudolph E. Tanzi, find quite convenient to refer to the triune brain theory for practical purposes [66]. Furthermore the sense of an "I" (as egocentric space) previous discussed could not exist without a corresponding "allocentric space" (as non-egocentric space), which neurophysiological evidences allocate to the hippocampus as an aspect of spatial representation, according to American-British neuroscientist John O'Keefe (1939-) [67].

\subsubsection{A Current Top-Down Approach}

The amount of information an individual can acquire in an instant or in a lifetime is finite, and minuscule compared with what the milieu presents; many questions are too complex to describe, let alone solve, in a practicable length of time. Traditionally, the horizons of accumulating ignorance are expanding faster than any person can keep up with. The proliferation of new sciences extends our powers of sense and thought, but their rigorous techniques and technical language hamper communication. The common field of knowledge becomes a diminishing fraction of the total store, stuffed by an overwhelming excess of irrelevant signs and symbols. It's happening something like already happened in the mass-media arena, where the "mass-mediatic scum" has totally overwhelmed our way to communicate, by the incessant growth of irrelevant information, visual and auditive requests. Laymen can find theirselves in a Horror Pleni situation [68], totally unable to discriminate the difference between an optimized encoding information-rich message and a random jumble of signs.

In the past five decades, trend in Systems Theory, in specialized research area, has slowly shifted from "General System Theory," introduced by Ludwig von Bertalanffy and classic single domain information channel transfer function approach (Shannon's channel, 1941 [69], with traditional computational model under either additive or multiplicative perturbation hypothesis [70], in Figure 2a), to the more structured ODR Functional Sub-domain Transfer Function Approach (by Observation, Description and Representation Functional Block, in Figure 2b [71]). Briefly, the ODR approach allows for fitting theoretical system design consideration to practical implementation needs much 
better (according to information "Input, Processing, Output" paradigm, respectively) than classic single domain channel approach. Thanks to the ODR approach, a deeper awareness about information acquisition and generation limitations by classical experimental observation process has been grown.

Figure 2. (a) Traditional Single Domain Channel (SDC) Transfer Function. (b) Decomposition of SDC Transfer Function into more structured ODR Functional Subdomain Transfer Function (Observation, Description and Representation Functional Blocks). (c) ODR Information Channel Co-domain Diagram for System Information Conservation.

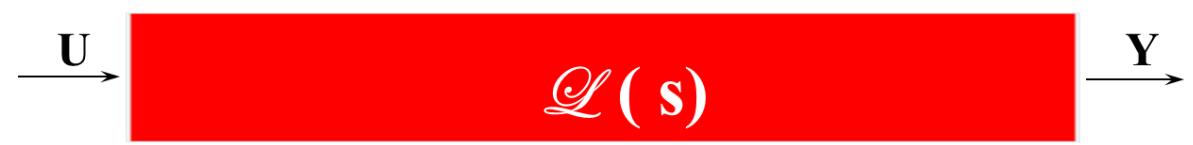

(a)

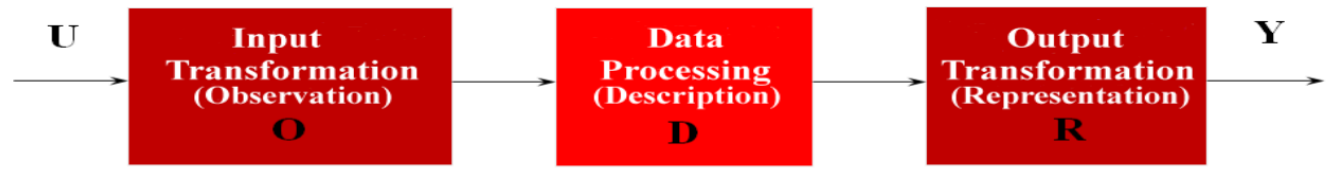

$$
\mathscr{Q}(\mathbf{s})=\mathbf{O} \cdot \mathbf{D} \cdot \mathbf{R}
$$

(b)

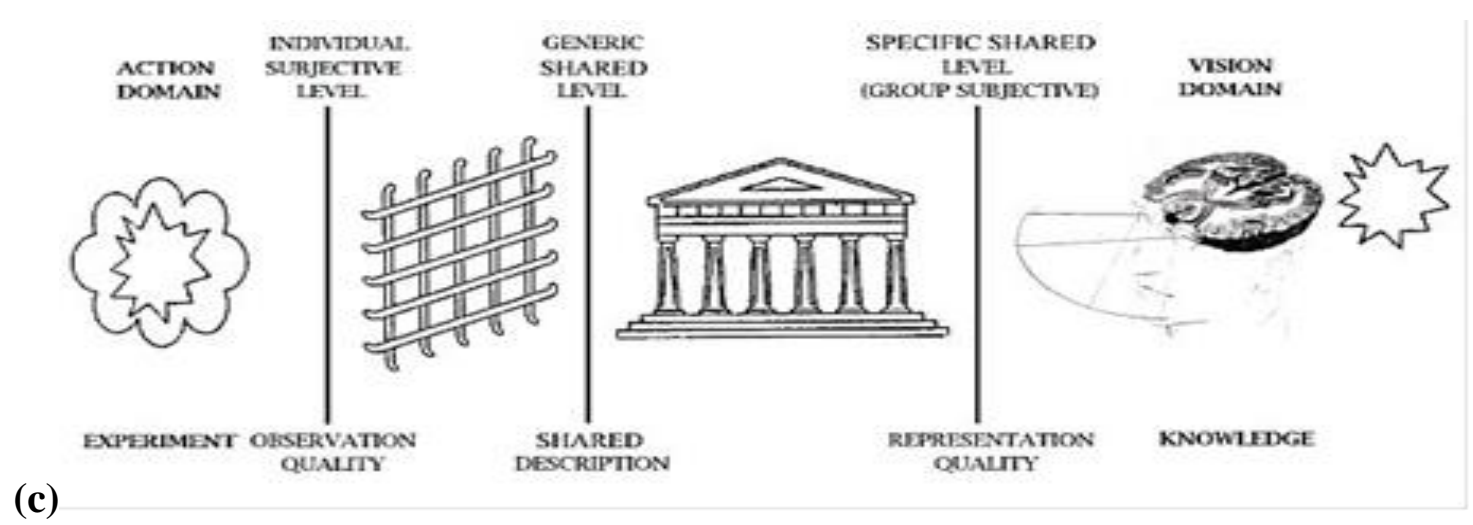

As a matter of fact, even the most advanced and sophisticated contemporary instrumentation system like "Soil Moisture Active Passive" (SMAP) satellite is using it. SMAP is designed to measure the intensity of electromagnetic radiation and equipped with an onboard computing system capable of crunching data equivalent to 192 million samples per second [72]. The new radiometer is expected to be integrated into NASA's SMAP spacecraft, along with a synthetic aperture radar system developed by JPL, and launched in 2014 finally [72]. The classical experimental observation process, even in highly ideal operative controlled condition, like the one achieved in contemporary most sophisticated and advanced experimental laboratories like CERN, can capture just a small fraction only, with misplaced precision, of overall ideally available information from unique experiment [73]. The remaining part is lost and inevitably added to something we call "background noise" or "random noise" usually, in every scientific experimental endeavor. The same is true for all other cascading functional blocks in the ODR transmission channel from source to destination, if careful information conservation countermeasure is not provided at each step. In Section 4.3 a convenient solution is proposed. 


\subsection{Human Communication}

The passage from "subjective worldview" to "shared worldview" is mediated by multifarious relations which human beings call communication for short. As a matter of fact, they can be grouped into two large areas: verbal and nonverbal communication. Accurate interpretation of human messages is made easier when nonverbal and verbal communication complement each other. Nonverbal cues can be used to elaborate on verbal messages to reinforce the information sent when trying to achieve communicative goals; messages have been shown to be remembered better when nonverbal signals affirm the verbal exchange.

\subsubsection{Verbal Communication (Language)}

Language [74]is the human ability to acquire and use complex systems of communication, and a language is any specific example of such a system. The scientific study of verbal language is called linguistics [75]. There are broadly three aspects to the study, which include language form, language meaning, and language in context [76]. The earliest known activities in the description of language have been attributed to Pānini around 500 BCE, with his analysis of Sanskrit in Ashtadhyayi [77]. The formal study of language has led to the growth of fields like psycholinguistics, which explores the representation and function of language in the mind; neurolinguistics, which studies language processing in the brain; and language acquisition, which investigates on how children and adults acquire a particular language. Symmetry properties play a fundamental role and affect word level structures and properties in analogous way to phoneme level and syllable level properties which create "double articulation" in human language, at least [78-80]. A semiotic code which has "double articulation" (as in the case of verbal language) can be analyzed into two abstract structural levels: a higher level called "the level of first articulation" and a lower level, "the level of second articulation" [81]. American linguist, philosopher, cognitive scientist, logician, Avram Noam Chomsky's (1928-) Theory of Syntax came after his criticism of probabilistic associative models of word order in sentences by Markov process approaches, in 1957 [82]. As a matter of fact, since 1951, the inadequacy of probabilistic LTR models (Markov process) had already been noticed by American psychologist and behaviorist Karl Spencer Lashley (1890-1958), who anticipated Chomsky's arguments, by observing that probabilities between adjacent words in a sentence have little relation to grammaticality of the string [83]. Ambiguity too provides a strong indication that sentences carry a structure. The treatment of numeric word, generator, relation and language by CICT largely draws its inspiration from many reliable research sources. Between them, the line of research started by Chomsky and French mathematician and Doctor of Western Medicine Marcel-Paul "Marco" Schützenberger (1920-1996) in the early 1960s occupies a singular place [84]. Those fascinating viewpoints invite us to use a mind open logic approach to find new, more convenient solutions to old problems, always!

\subsubsection{Nonverbal Communication}

Nonverbal communication is the process of communication through sending and receiving wordless (mostly visual) cues between people. It is sometimes mistakenly referred to as body language (kinesics), but nonverbal communication encompasses much more, such as use of voice 
(paralanguage), touch (haptics), distance (proxemics), and physical environments/appearance [85]. In case of figures or image sequences, Italian semiotician Umberto Eco (1932-) argued that "Iconic Language" has a "triple articulation": Iconic Figures, Semes (combinations of Iconic Figures), and Kinemorphs (combination of Semes), like in a classical movie [86,87]. Typically overlooked in nonverbal communication are proxemics, or the informal space around the body and chronemics: the use of time. Not only considered eye contact, oculesics comprises the actions of looking while talking and listening, frequency of glances, patterns of fixation, pupil dilation, and blink rate. Even speech contains nonverbal elements known as paralanguage, including voice quality, rate, pitch, volume, and speaking style, as well as prosodic features such as rhythm, intonation, and stress. Likewise, written texts have nonverbal elements such as handwriting style, spatial arrangement of words, or the physical layout of a page. However, much of the study of nonverbal communication has focused on interaction between individuals [88], where it can be classified into three principal areas: environmental conditions where communication takes place, physical characteristics of the communicators, and behaviors of communicators during interaction. Nonverbal communication involves the processes of encoding and decoding. Encoding is the act of generating the information such as facial expressions, gestures, and postures. Decoding is the interpretation of information from received sensations from previous experiences[88]. Only a small percentage of the brain processes verbal communication. As infants, nonverbal communication is learned from social-emotional communication, making the face rather than words the major organ of communication. As children become verbal communicators, they begin to look at facial expressions, vocal tones, and other nonverbal elements more subconsciously. Culture plays an important role in nonverbal communication, and it is one aspect that helps to influence how learning activities are organized. In many Indigenous American Communities, for example, there is often an emphasis on nonverbal communication, which acts as a valued means by which children learn. In this sense, learning is not dependent on verbal communication; rather, it is nonverbal communication which serves as a primary means of not only organizing interpersonal interactions, but conveying cultural values, and children learn how to participate in this system from a young age [89]. Nonverbal communication represents two-thirds of all communication [90]. Nonverbal communication can portray a message both verbally and with the correct body signals. Body signals comprise physical features, conscious and unconscious gestures and signals, and the mediation of personal space [90]. The wrong message can be established if the body language conveyed does not match a verbal message. Nonverbal communication strengthens a first impression in common situations like attracting a partner or in a business interview: impressions are on average formed within the first four seconds of contact [90]. First encounters or interactions with another person strongly affect a person's perception [91]. When the other person or group is absorbing the message, they are focused on the entire environment around them, meaning the other person uses all five senses in the interaction: $83 \%$ sight, $11 \%$ hearing, $3 \%$ smell, $2 \%$ touch and $1 \%$ taste [92].

\subsection{Shared Worldview}

According to biomedical cybernetics point of view, to get closer to real computational information conservation, ODR Functional Sub-domain Transfer Function block diagram (Figure 2b) must be completed by a corresponding irreducible complementary "ODR Information Channel Co-domain 
Diagram" to get reliable strategic overall information functional closure (Figure 2c) [10]. Remembering that there is no information without representation, we realize that Observation, Description and final Representation blocks mean different kind of representations. They are representations at different word precision. Starting at the Observation step, interaction between an Experimental Field with an Action Domain is established and discrete data are captured. Observation is properly described as a fact-finding rather than a fact-collecting procedure, because the idea of finding includes both selection by controlled perturbation and efficient structured collection. The quality of Observation does then depend both on the degree of completeness by which experimental folded information is allowed to be efficiently captured from our experimental field into our subjective structured Action Domain and then properly formatted, according to Observer experience and shared rules, and on Observer Representation arbitrary precision (System Input Transformation), to be passed to next processing block. Then the second step, Description, can format and formalize folded subjective observation into an unfolded systemic minimal insured Representation word precision, to be shared by the majority of interacting entities which use the same formal language at the same word precision to communicate (Overall System State), to be passed to the last step. Finally, the quality of the Representation stage does depend again both on the degree of completeness by which unfolded information is allowed to be focused and re-folded to be efficiently presented to specific shared human knowledge and on output Representation word precision (System Output Transformation). Then a validation process can start and an endorsement can be assigned eventually, according to convenient Representation support quality level for scientific knowledge synthesis, cultural analytics, information/perceptual aesthetics, etc. [80,93]. The ODR approach has contributed to create deeper awareness about traditional information acquisition, formalization and reproduction process limitations, constrained by classical experimental observation and new multimedia data acquisition and reproduction implementation. As a matter of fact, traditional rational number system $\boldsymbol{Q}$ properties allow to generate an irreducible co-domain for every computational operative domain used. Then, all computational information usually lost by using the classic information approach, based on the traditional noise-affected data model stochastic representation, can be captured and fully recovered to arbitrary precision by a corresponding evolutive irreducible complementary co-domain, step-by-step. Co-domain information can be used to correct any computed result, achieving computational information conservation (theoretically, virtually noise-free data), according to CICT Infocentric Worldview [10]. A further detailed description of the diagrams of Figure 2 far exceeds the scope of present discussion and the interested reader is referred to [71].

\section{Reflexive and Reflective Processes}

Over the years, at least three systemic theories of reflexive processes have been created in different disciplined areas (i.e management, sociology and economy) [94]:

1) Heinz von Foerster (1911-2002), beginning in 1974, advocated including the observer in the domain of science. He called this line of inquiry "second order cybernetics" [4].

2) Vladimir Lefebvre (1936-) proposed the existence of two systems of ethical cognition and called the activity of selecting the appropriate ethical system for the occasion "reflexive control" [95]. 
3) George Soros (1930-) described both economic and political systems as being composedof individuals who are actors as well as observers [96].

Drawing upon the idealist philosophical tradition von Foerster noted that our knowledge of the world is mediated by our senses, and hence the "reality" that we describe is the result of interpretations of sensory experience. Indeed, he said that people are responsible not only for their actions but for the interpretations of the world they have constructed. He claimed that a theory of biology should be able to explain the existence of a theory of biology [97]. Lefebvre created a mathematical theory of cognition and, depending on the operator one chose $(+$ or $*)$, he noted that there are two systems of ethical cognition. In the first ethical system a good end does not justify a bad means. In the second ethical system it does. Lefebvre claims that people are "imprinted" with one of the two ethical systems at an early age. Throughout life one's first response is to act in accord with the imprinted ethical system. However, one can learn the other ethical system and act in accord with it, when one realizes that the imprinted system is not working [95]. George Soros's reflexivity theory is quite compatible with second order cybernetics. Indeed his work shows how to apply ideas in second order cybernetics to economics, finance, and political science [96]. His approach to finance is more holistic than most current work in finance. He does not emphasize mathematical models but rather sees finance as a human player game with himself as a participant [98].

As a matter of fact, reflexivity has always presented a twofold meaning at least, in scientific literature. From one end, usually, for physical systems, "reflexion" is defined as the return of light or sound waves from a surface, the action of bending or folding back, or an idea or opinion made as a result of meditation [99]. "Reflexive" is defined as something turned back on itself, a relation that exists between an entity and itself. "Self-reference" in mathematics indicates a statement that refers to itself, for example, a set that contains itself. So, usually, in mathematics "reflexion" becomes "reflection" and may be quite ambiguous for mathematicians to be interpreted immediately. In fact, traditionally, in mathematical logic, such statements lead to paradox, a form of inconsistency. In the informal fallacies self-referential statements are considered poor form. To avoid those problems, the solution is to move from category representation to process representation approach. In fact, a social scientist who formulates a theory of a society in which he or she is a member is making self-referential statements. An investor who makes trades that alter price is engaged in a reflexive process. Reflexivity occurs in social systems when an actor observes and thinks about his or her actions and their consequences and then modifies his or her behavior [100]. On the other end, in geometry, a reflection (also spelled reflexion) is a mapping from a Euclidean space to itself that is an isometry with a hyperplane as set of fixed points; this set is called the axis (in dimension 2) or plane (in dimension 3) of reflection. The image of a figure by a reflection is its mirror image in the axis or plane of reflection. For example the mirror image of the small Latin letter "p" for a reflection with respect to a vertical axis would look like "q". Its image by reflection in a horizontal axis would look like "b". A reflection is an involution: when applied twice in succession, every point returns to its original location, and every geometrical object is restored to its original state. The term "reflection" is sometimes used for a larger class of mappings from a Euclidean space to itself, namely the non-identity isometries that are involutions. Such isometries have a set of fixed points (the "mirror") that is an affine subspace, but is possibly smaller than a hyperplane. For instance a reflection through a point is an involutive isometry 
with just one fixed point; the image of the letter "p" under it would look like a "d". This operation is also known as a central inversion [101], and exhibits Euclidean space as a symmetric space. In a Euclidean vector space, the reflection in the point situated at the Origin is the same as vector negation. Other examples include reflections in a line in three dimensional space. Typically, however, unqualified use of the term "reflection" means reflection in a hyperplane. A figure which does not change upon undergoing a reflection is said to have reflectional symmetry.

According to neuroscience, two neurocognitive systems are involved in brain reflective and reflexive processing. On the one hand, these two systems correspond to cognitive processing dichotomies that have been around for a few generations: automatic vs. controlled and implicit vs. explicit. At the same time, these old dichotomies are limited in their ability to provide adequate treatment to the positive contributions of each half of the dichotomy. Instead, these formulations define the dichotomy as one or more continua and thus both ends of the continua are defined as the presence or absence of particular characteristics (effort, intention, awareness). By focusing on the neural basis of these systems, links can be made to the known computational characteristics of these systems and these characteristics provide us with important clues as to why the two systems provide us with the outputs they do. Neuroimaging allows the study of the ongoing interactions between the two systems. According to Matthew Lieberman, at Department of Psychology, University of California, Los Angeles, the neural correlates associated with these two types of processes are the X-system (for the $\mathrm{X}$ in reflexive) and the $\mathrm{C}$-system (for the $\mathrm{C}$ in reflective) [102]. The $\mathrm{X}$-system is composed of the amygdala, basal ganglia, and lateral temporal cortex to form a very efficient knowledge base about the social and affective characterics of social phenomena that often sets into motion behaviors based on extensive learning histories that have accumulated slowly over time. The X-system contains our implicit theories and expectations that allow us to interface smoothly with the world, seamlessly promoting our goals and avoiding our foes. The C-system is designed to sense the floundering of the $\mathrm{X}$-system and intervenes when appropriate. Of course, in the modern world the C-system is activated much of the time regardless of the X-system's preparedness. That is to say, while the C-system may have evolved to come to the X-system's rescue, the C-system has clearly taken on a life of its own in a world in which nearly every external cue is designed to evoke some degree of C-system processing. Moreover, the rationalist tradition of western society looks down upon the use of intuition [103-106] and consequently people may tend to rely on C-system processing even when X-system processing would suffice. In contrast to the X-system's efficiency with social phenomena that conform to its generalities, the C-system is critical for handling the exceptions to the rules [107]. The C-system is composed of three neurocognitive mechanisms that work closely together: anterior cingulate cortex, prefrontal cortex, and the medial temporal lobe (including the hippocampus). Beginning with modern science and empiricism, human beings question reality and confront borders that an empirical (or scientific) method simply cannot transcend. At this point, the individual faces a choice: sink into despair and resignation, or take a leap of faith toward something called "Transcendence" by German psychiatrist and philosopher Karl Theodor Jaspers (1883-969) [108]. In making this leap, individuals confront their own limitless freedom ("Existenz"), and can finally experience authentic existence[108, 109]. Transcendence (paired with the term "The Encompassing" in later works) is, for Jaspers, that which exists beyond the world of time and space. Jaspers himself continually stressed the necessity of 
recognizing the validity of the concepts both of subjectivity and objectivity as an eternal dichotomy[110,111].

\section{Asymmetry and Polynomial Mirroring}

When dealing with computational digits a few operational subtleties do exist. A simple example can clarify these subtleties immediately. Let us consider a function $y=f(x)$ depicted in Figure 3 (continuous trait), by a representation on a bidimensional Euclidean space (half plane). In this specific case $y=e^{x}$, with the usual mathematical meaning for "e."

Figure 3. Usual mathematical function representation by bidimensional Euclidean space (2d).

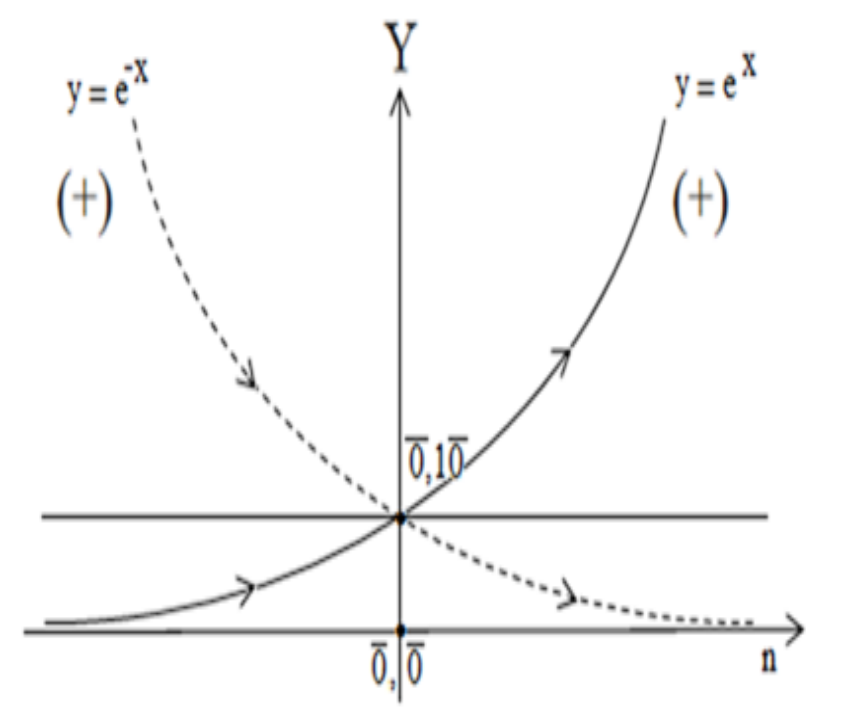

If we consider this function like a walking path from your home, starting on the left side, you can go from left to right, passing through the point $(0.0,1.0)$ that is mapped to the Origin $(0.0,0.0)$ using the same orientation of abscissa n, obtaining a divergent route, or you can reverse your way, going back, returning to home, obtaining a convergent route, back to where you started. Now, if we consider a reflection of our function with respect to the vertical axis $\mathrm{Y}$, we get the situation depicted in Figure 4a.

Figure 4. (a) Reflection of our function with respect to the vertical axis $\mathrm{Y}$ on bidimensional Euclidean space (2d). (b) Self-Reflection of our function with respect to the vertical axis $\mathrm{Y}$ on bidimensional Euclidean space (2d).

(a)

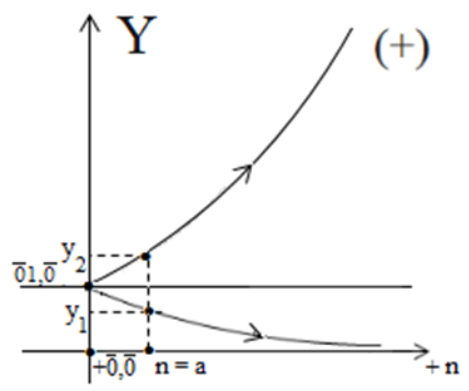

(b)

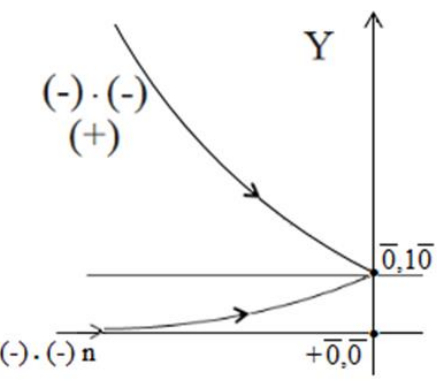


Your space left side with respect to $\mathrm{Y}$ got turned back, folded to the right one. This time your starting point is no more on the left side, but on a point on the right side, corresponding to the original one by reflection. If you start your walking, this time you can go back and forth through points with $\mathrm{Y}<=1.0$ only: You are confined into a subspace. So, you got confined by reflection and you lost your full space freedom! So, to be creative, have we any possibility, as living organism, to restore our original space? As always, when you know your representation system limitations, you can use that knowledge to your advantage. So, we can use automatic system polynomial mirroring to our own advantage by self-reflexion! We can operate a self-reflection with respect to the vertical axis $Y$, to get the mirrored function of that in Figure $4 a$, obtaining the function in Figure 4b. Now, conveniently combining Figure $4 \mathrm{a}$ and Figure $4 \mathrm{~b}$ we obtain our final result depicted in Figure 5. If you compare Fig.07 to original Fig.04, you realize that, in some way, you have restored something that resembles your initial space. Apparently, you are no longer confined anymore to you subspace, you have recovered your space freedom! Or not? Well, by mathematics we could say many things to fill a new book, but from living organism point of view, that is an outstanding result: by at-least two biotransducers conveniently coupled, you can represent your working space in full with no subspace confinement, even by using structured polynomials for your information representations!

Figure 5. Convenient combination of Figure $4 \mathrm{a}$ and Figure $4 \mathrm{~b}$ to recover full space freedom on bidimensional Euclidean space (2d).

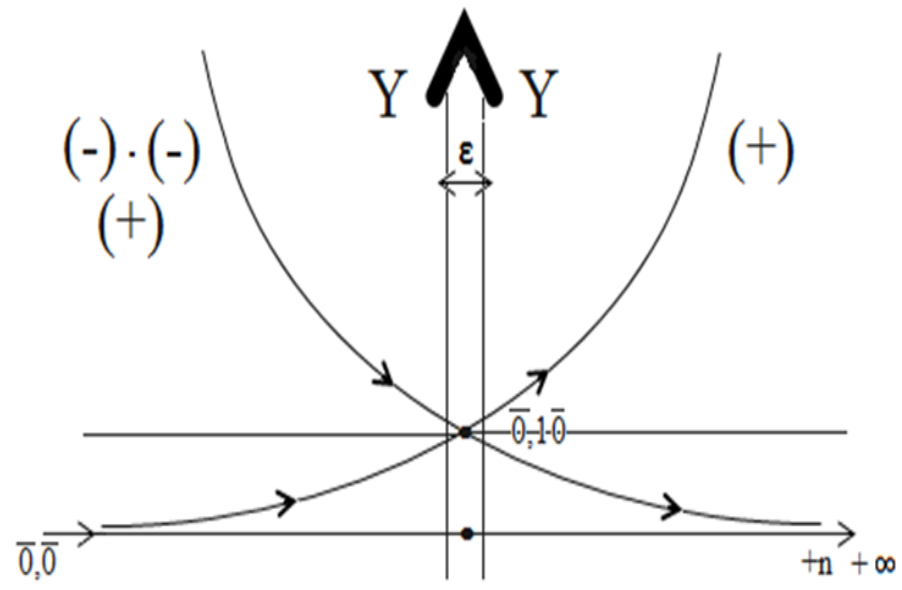

\section{Ontological Uncertainty Management Solution}

There are many ways that human intelligence differs from that of animals, but one of the most obvious is our level of self-awareness. In scientific literature, this faculty is often referred to as Introspection or Metacognition, in a wider meaning. It is the ability to self-reflect, to know about yourself. Introspection seems to be quite core to who we are. There have been hints of this capacity in dolphins and monkeys, for instance, although sceptics say there could be other explanations for the results. Scanning the brain of humans while they carry out metacognitive tasks suggests the seat of this ability lies in part in our prefrontal cortex, at the front of our head, mainly. According to our analysis in previous sections, two coupled fundamental processes are at the core of human mind: 
Process A: Wiring and re-wiring of a Focused Optimal Path (FOP) to creatively reach a planned goal.

Process B: Process A rational assessment and endorsement (checking + FOP updating if needed).

Process A is fed by definition doubting and compromising mainly; the availability of an environmental chaotic information redundant support is required (RATL, Right Anterior Temporal Lobe): emotion $\rightarrow$ FOP (re-)wiring $\rightarrow$ sensation $\rightarrow$ action (survival oriented, open logic process).

Process B is based on opposing, complementing and commanding; clearly defined formal rules are required to actively operate: emotion $\rightarrow$ sensation $\rightarrow$ perception $\rightarrow$ action (learning oriented, closed logic process), (i.e. solution path logical articulation $\rightarrow$ checking $\rightarrow$ difference learning).

In Section 3, we already saw that it is much better to consider ontological uncertainty [38] as an emergent phenomenon out of a complex system [14]. Then, our ontological perspective can be thought only as an emergent, natural operating point out of, at least, the interaction dichotomy of two coupled irreducible complementary ideal asymptotic concepts: a) reliable predictability (closed logic subsystem) and b) reliable unpredictability (open logic subsystem). From a top-level management perspective, the reliable predictability concept can be referred to traditional system reactive approach (fixed or closed logic subsystem) and operative management techniques, while the reliable unpredictability concept can be associated to system proactive approach (open logic subsystem) and strategic management techniques. To behave realistically (i.e. to capture natural event dynamics), system must guarantee both Logical Closure (to get Rational Thinking, to learn and prosper) and Logical Aperture (to get EI and EC, to survive and grow), both fed by environmental noise (better... from what human beings call "noise") [10].

Figure 6. Operating Point can emerge as a new Trans-disciplinary Reality Level, based on the Interaction of Two Complementary Irreducible Management Subsystems.

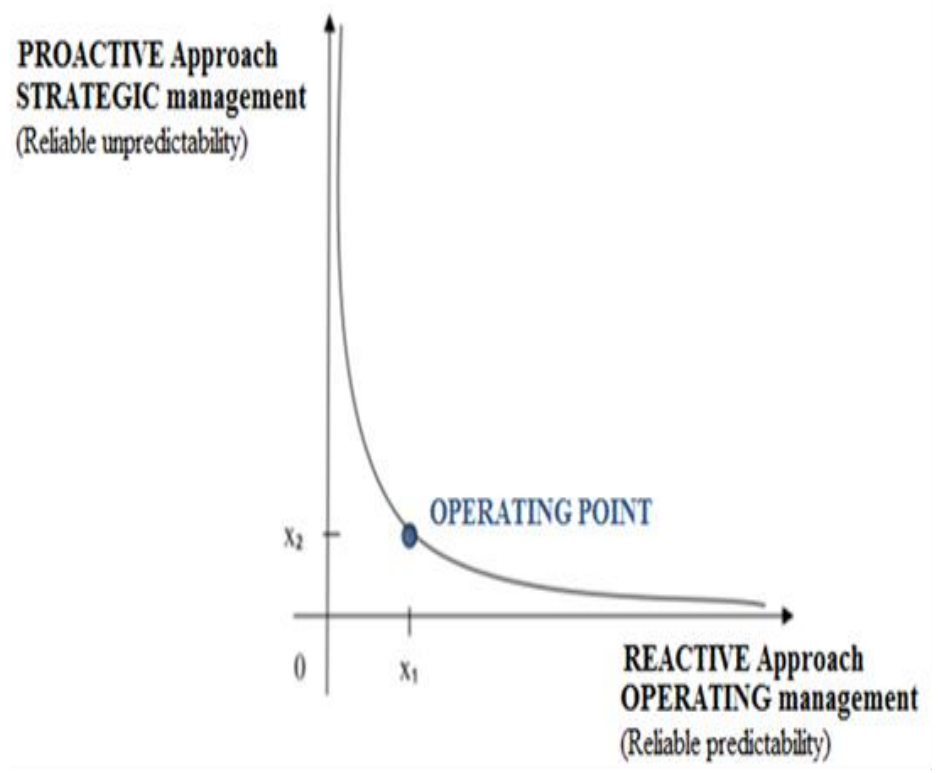




\section{Open Logic Solution}

To provide EPM with an evolutive structure (open logic), we can follow many different approaches. The Classic EPM associated Boolean algebra $B_{3}$ can be represented (LTR) by a cube $C_{3}$ in $R^{3}$. By remembering the notions of "logical space" proposed by Wittgenstein [112] and of "hypercube" proposed by Pólya [113], it is straightforward to consider a Boolean-valued model, as the simplest extension of EPM. A Boolean-valued model is a generalization of the ordinary Tarskian notion of structure from model theory [114]. In a Boolean-valued model, the truth values of propositions are not limited to "true" and "false", but instead take values in some fixed complete Boolean algebra. Booleanvalued models were introduced by Dana Scott, Robert M. Solovay, and Petr Vopěnka in the 1960s in order to help understand Paul Cohen's method of forcing, presented in 1963 [115]. They are also related to Heyting algebra semantics in intuitionistic logic [116]. The problem of whether a given equation holds in every Heyting algebra was shown to be decidable by S. Kripke in 1965 [117]. The precise computational complexity of the problem was established by R. Statman in 1979, who showed it was PSPACE-complete [118] and hence at least as hard as deciding equations of Boolean algebra (shown NP-complete in 1971 by S. Cook [119], and conjectured to be considerably harder. The elementary or first-order theory of Heyting algebras is undecidable [120]. It remains open whether the universal Horn theory of Heyting algebras, or word problem, is decidable [121]. For the word problem it is known that Heyting algebras are not locally finite (no Heyting algebra generated by a finite nonempty set is finite), in contrast to Boolean algebras which are locally finite and whose word problem is decidable. It is unknown whether free complete Heyting algebras exist except in the case of a single generator where the free Heyting algebra on one generator is trivially completable by adjoining a new top. A Boolean algebra of order $2^{n}$, called $B_{n}$, is graded of rank $n$ [122], and can be represented as a hypercube or $n$-cube $C_{n}$, in $n$-dimensional Euclidean space $R^{n}$, for $n=0,1,2,3,4, \ldots, \infty, n \in N$. Our main idea is to achive EPM open logic model behaviour (logic dynamics) by providing EPM with the asymptotic process of the structured sequence of locally finite Boolean algebras for $n \rightarrow \infty$ teorethically. In Figure 7, the process to obtain successive n-dimensional hypercubes up to $n=4$ is depicted. For $\mathrm{n}=4$, the Boolean algebra is represented as a four-dimensional hypercube $\mathrm{C}_{4}$. We again can employ the "conventional" LTR coordinate mapping c : $\{0 ; 1\}^{4} \rightarrow \mathrm{R}^{4}$. This can be generalized to any number of dimensions. In fact, the process of sweeping out volumes (Figure 7) can be formalized mathematically as a Minkowski sum: the n-dimensional hypercube is the Minkowski sum of $n$ mutually perpendicular unit-length line segments, and is therefore an example of a zonotope. Then, $n$ dimensional hypercubes geometrical information can be projected to convenient projection planes to study the local beahaviour of their connection components as graphs. For instance, in Figure 8, the related Petrie polygon Orthographic projections up to $n=8$ are shown.Then, the graph of the nhypercube's edges is isomorphic to the Hasse diagram of the (n-1)-simplex's face lattice. This can be seen by orienting the n-hypercube so that two opposite vertices lie vertically, corresponding to the (n1)-simplex itself and the null polytope, respectively. Each vertex connected to the top vertex then uniquely maps to one of the (n-1)-simplex's facets ( $n-2$ faces), and each vertex connected to those vertices maps to one of the simplex's n-3 faces, and so forth, and the vertices connected to the bottom vertex map to the simplex's vertices. This relation may be used to generate the face lattice of an (n-1)- 
simplex efficiently, since face lattice enumeration algorithms applicable to general polytopes are more computationally expensive.

Figure 7. (0) - A point is a hypercube of dimension zero. (1) - If one moves this point one unit length, it will sweep out a line segment, which is a unit hypercube of dimension one. (2) - If one moves this line segment its length in a perpendicular direction from itself; it sweeps out a 2-dimensional square. (3) - If one moves the square one unit length in the direction perpendicular to the plane it lies on, it will generate a 3-dimensional cube. (4) - If one moves the cube one unit length into the fourth dimension, it generates a 4-dimensional unit hypercube (a unit tesseract).

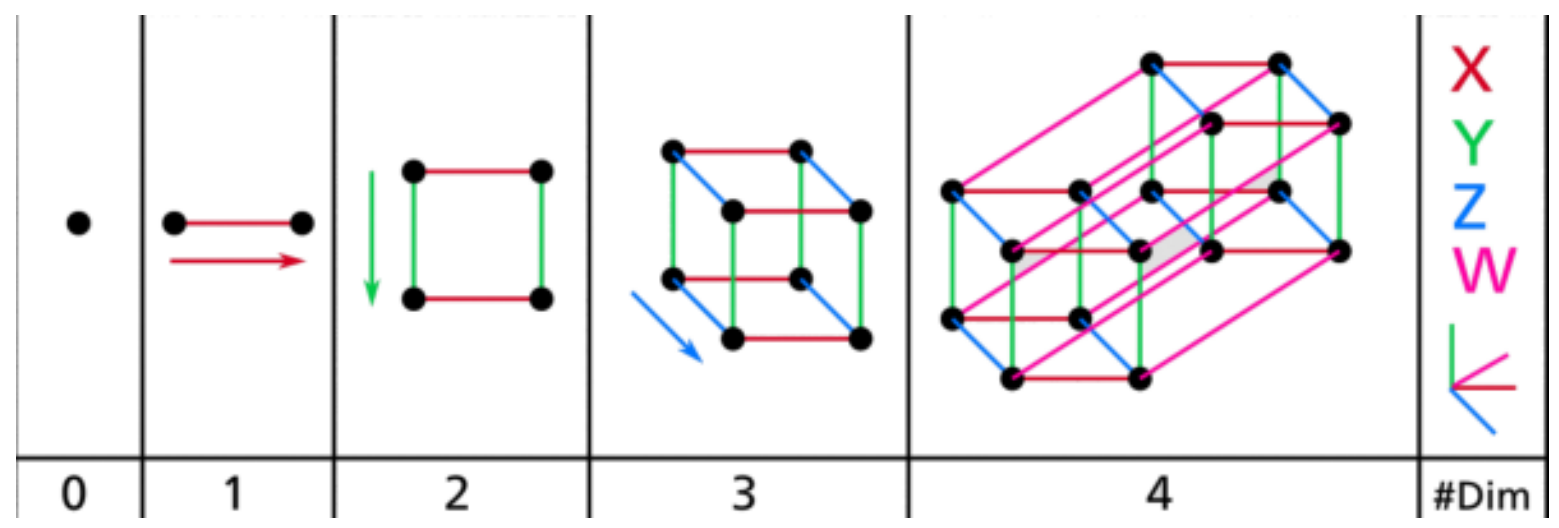

Figure 8. N-dimensional Hypercube Petrie polygon Orthographic projections from $\mathrm{n}=1$ up to $\mathrm{n}=8$, as graphs.

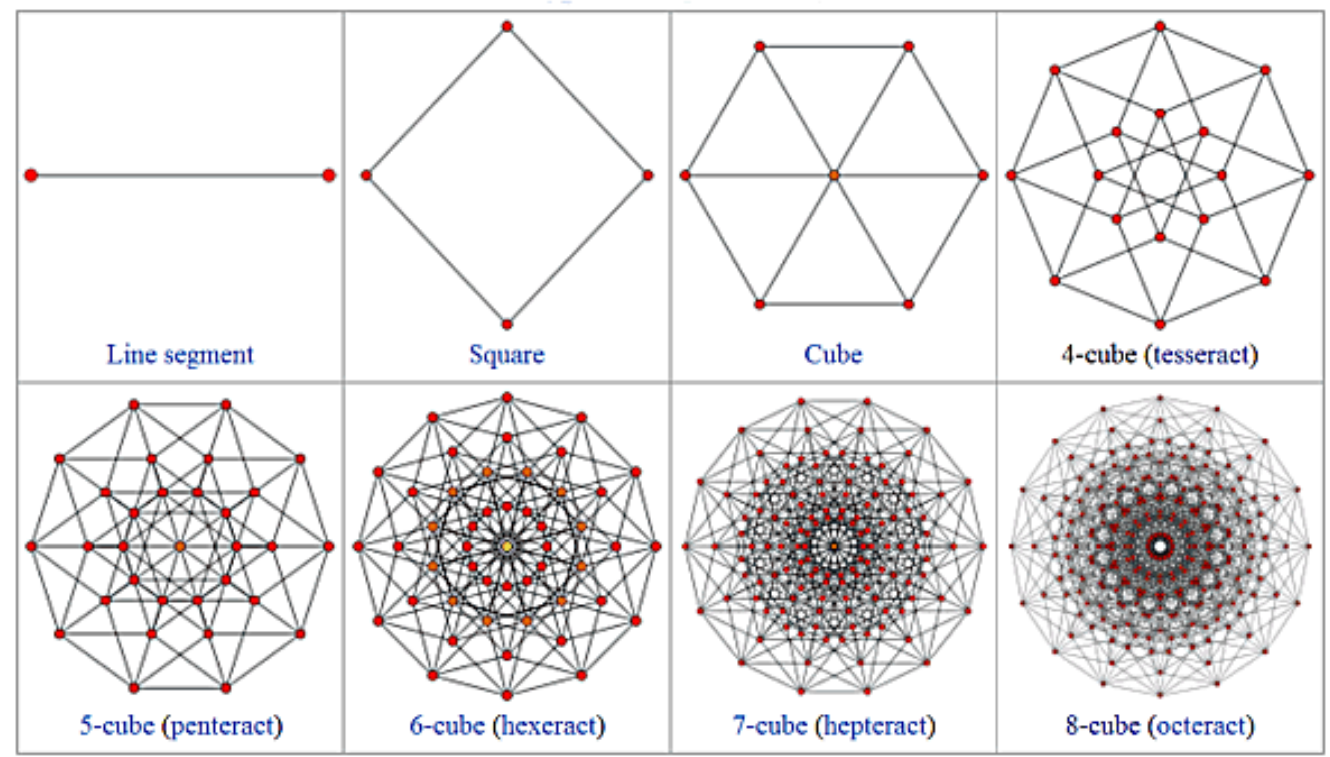

Then, the Hasse diagram for any $B_{n}$ can be seen as (n-1)-dimensional vertex-first projections of these hypercubes. Although Hasse diagrams are simple as well as intuitive tools for dealing with finite posets, it turns out to be rather difficult to draw "good" diagrams. The reason is that there will in 
general be many possible ways to draw a Hasse diagram for a given poset. The simple technique of just starting with the minimal elements of an order and then drawing greater elements incrementally often produces quite poor results: symmetries and internal structure of the order are easily lost. In Figure 9 this issue is demonstrated by considering the power set of a 4-element set ordered by inclusion ( $\subseteq$ ) of a 4-cube or tesseract. There are four different Hasse diagrams for this partial order. Each subset has a node labelled with a binary encoding that shows whether a certain element is in the subset (1) or not $(0)$.

Figure 9. Hasse diagrams (see text). The first diagram on the left makes clear that the power set is a graded poset. The second diagram has the same graded structure, but by making some edges longer than others, it emphasizes that the 4-dimensional cube is a union of two 3-dimensional cubes. The third diagram shows some of the internal symmetry of the structure. In the fourth diagram, on the right, the vertices are arranged like the fields of a $4 \times 4$ matrix.
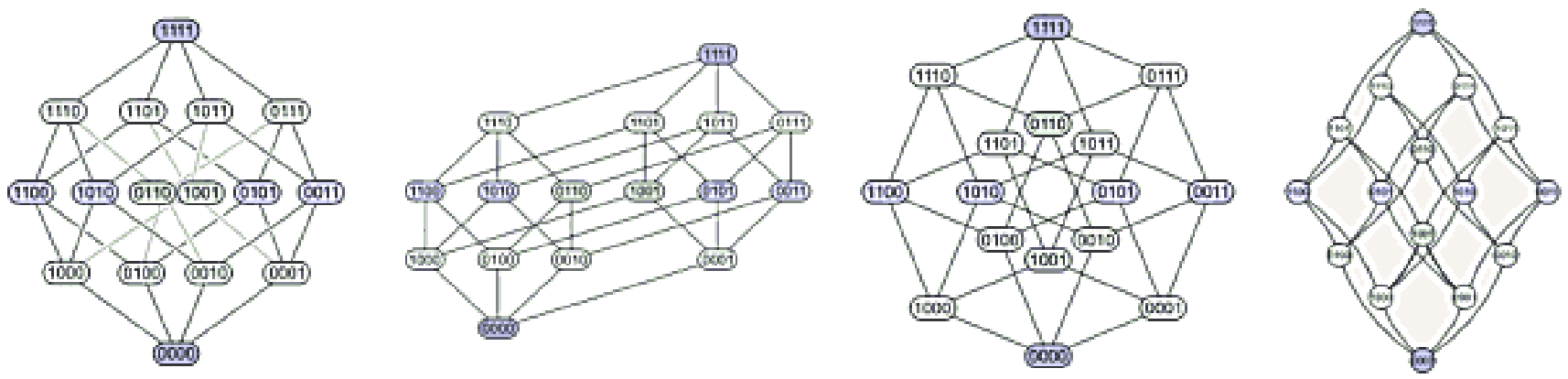

Therefore, whether the diagram is Hasse or Aristotelian depends on our choice of the projection axis $[123,124]$. For a full definition of these structures, by a teorethical perspective, one should look to Judson, at least [125]. Finally, please, note, that the power set $\mathrm{P}\left(\mathrm{B}_{\mathrm{n}}\right)$ of any locally finite Boolean algebra $B_{n}$ can be thought even as a Self-Reflective Functional Logical Closure for the power set $P\left(B_{n-}\right.$ 1) of preceeding locally finite Boolean algebra $B_{n-1}$. According to Computational Information Conservation Theory (CICT), this property is fundamental to achieve overall model systemic resilience and antifragility behaviour.[10,11,71]

\section{Conclusions}

Now, EPM can be thought as a reliable starting subsystem (closed logic, operative management, Figure 6) to initialize a process of continuous self-organizing and self-logic learning refinement (open logic, strategic management subsystem, Figure 6). As already described in previous sections, this method can capture natural logic dynamics behaviour, as function of specific unpredictable perturbance, unknown at system design level. Though the hypercube logical geometry seems to be a straight-forward method to depict the logical relations in propositional logic, further research must be planned to go beyond this first approach of the notation. Future studies ought to validate empirically the contribution of this logical geometry approach to the understanding of logical relationships, notably in educational settings. The intuitive character of the related algebra to apprehend logical relations must be tested in comparison with classical methods of learning. Through the hypercube geometric 
algebra, we propose a notation that goes beyond a format distinction and constructed with the purpose to facilitate inferences either on a diagrammatic representation, or a lexical one. The latter particularly allows operations on complex propositions within hypercube with more than three dimensions, mentally difficult to imagine. This algebra, by posting directly configurations in which a complex proposition is true, can explicitly represent all mental models, in the sense of Johnson-Laird [126], 2001) necessary for the apprehension of a proposition in all its complexity. In agreement to Morineau [127], we think that this algebra could represent a tool for assisting work activities that involve inductive reasoning, like problem- and case-based reasoning in medical diagnosis [128], and subject profiling in psychiatry and psychotherapy [129-131]. More specifically, from a biomedical engineering perspective, fault diagnosis task [132] and troubleshooting on logical networks [133] could be areas of application for reliable testing and validation of the presented EPM extension.

\section{Conflicts of Interest}

The authors declare no conflict of interest.

\section{References and Notes}

1. De Giacomo, P.; Silvestri, A.; Corfiati, L.; Lefons, E.; Pierri, G.; Pazienza, M. T.; Tangorra, F. Versuch einer interaktiven "logischen" Therapie. Ein theorisches Modell fuer Therapie und Bevertung der Veraenderung. Familiendynamik 1981, 2, 148-157.

2. Lefons, E.; Pazienza, M.T.; Silvestri, A.; Tangorra, F.; Corfiati, L.; De Giacomo, P. An Algebraic Model for Systems of Psychically Interacting Subjects. Proceeding of I.F.A.C. Workshop, Compiègne, France. In: Ination and Systems; Pergamon Press:Oxford, 1977.

3. Silvestri, A.; De Giacomo, P. A Computerized Laboratory for Approach to Relational Psychoterapy. In: Proc. Congress on Medical Informatics; Berlin, 1979.

4. von Foerster, H. Cybernetics of Cybernetics; University of Illinois Press: Urbana, IL, 1974.

5. Sakhnini, V.; Mich, L.; Berry, D.M. Group Versus Individual Use of an Optimized and the Full EPMcreate as Creativity Enhancement Techniques for Web site Requirements Elicitation. In Proceedings of CreaRE'13 - Creativity in Requirements Engineering, Essen, 2013; pp. 15-30.

6. De Giacomo, P.; Mich, L.; Santamaria, C.; Sweeney, L.G.; De Giacomo, A. Information Processing. In Paradigms in Theory Construction; Springer-Verlag: NewYork, 2012; pp. 341-363.

7. Sakhnini, V.; Mich, L.; Berry, D.M. The effectiveness of an optimized EPMcreate as a Creativity Enhancement Technique for Website Requirements Elicitation. Requirements Engineering 2012, Volume 17, 3, 171-186.

8. Mich, L.; Anesi, C.; Berry, D. Applying a Pragmatics-Based Creativity-Fostering Technique to Requirements Elicitation. Requirements Engineering 2005, Volume 10, 4, 262-275.

9. De Giacomo, P.; Mich, L.; Storelli, M.; De Nigris, S.; De Giacomo, A.; Tarquinio, C.; Masellis, R. A method of counseling on line using the Elementary Pragmatic Model. Proceedings of AATP 2002, Philadelphia, Pennsylvania. In Changing Our Minds, American Association for Technology in Psychiatry, New York, 2002; p. 1-6.

10. Fiorini, R.A. How Random is Your Tomographic Noise? A Number Theoretic Transform (NTT) Approach. Fundamenta Informaticae 2014, Volume 135, 3-4, 1-36. 
11. Fiorini, R.A.; Laguteta, G. Discrete Tomography Data Footprint Reduction by In-formation Conservation. Fundamenta Informaticae 2013, Volume 125, 3-4, 261-272.

12. Fiorini, R.A.; Santacroce, G.F. A post-Bertalanffy Systemics Healthcare Competitive Framework Proposal. In Proceedings 12th ICIMTH, International Conference on Informatics, Management, and Technology in Healthcare, Athens, July 10-13, 2014; Mantas, J., Ed.

13. Fiorini, R.A.; Santacroce, G.F. Safety and Effectiveness Health Systemic Governance by HICT Natural Framework. In Proceedings International Conference on Biomedical Informatics, Milano, May 8-9, 2014; Pinciroli, F., Ed.

14. Fiorini, R.A.; Santacroce, G.F. Economic Competitivity in Healthcare Safety Management by Biomedical Cybernetics ALS. In Procedings International Symposium, The Economic Crisis: Time For A Paradigm Shift -Towards a Systems Approach, Universitat de València, January 24-25, 2013.

15. Lowenthal, D. Geography, Experience, and Imagination: Towards a Geographical Epistemology. Annals Association of American Geographers 1961, Volume 51, 3, 241-260.

16. Blank, A. A. Axiomatics of Binocular Vision. The Foundations of Metric Geometry in Relation to Space Perception. Journal of the Optical Society of America 1958, 48, 328-334.

17. Gibson, J. J. Perception as a Function of Stimulation; McGraw-Hill: New York, 1959; 456-501.

18. Luneburg, R. K. Mathematical Analysis of Binocular Vision; Princeton Univ. Press: Princeton NJ, 1947.

19. Good, I. J.: Why Physical Space Has Three Dimensions. British Journal for the Philosophy of Science 1959, 9, 317-319.

20. Hertz, R. Death and the Right Hand; Free Press: Glencoe (IL), 1960.

21. Whitrow, G. J. Why Physical Space Has Three Dimensions. British Journal for the Philosophy of Science 1955, 6, 13-31.

22. Cassirer, E. An Essay on Man: Introduction to a Philosophy of Human Culture; Yale University Press: New Haven, 1944.

23. Filloux, J.-C. The Problem of Space with Particular Emphasis on Specific Sensory Spaces. La Nature 1957, 85, 403-407,438-443,490-493.

24. Revesz, G. The Problem of Space with Particular Emphasis on Specific Sensory Spaces. American Journal of Psychology 1937, 50, 434-436.

25. Born, M. Natural Philosophy of Cause and Chance; Clarendon Press: Oxford, 1949.

26. Russell, B. Human Knowledge: Its Scope and Limits,; Simon and Schuster: New York, 1948.

27. Fiorini, R.A. Bio-transduction Systems. In Wellbeing Technology Assessment Seminars, Bioengineering Department, Politecnico di Milano, Milano, 2009.

28. Wildberger, N. J. Universal Hyperbolic Geometry I: trigonometry. Geom. Dedicata 2013, 163, 215-274.

29. Fiorini, R. A. Sanità 5.0, La visione evolutiva, Parte A: visione multiscala; CUSL Collana Scientifica: Milano, Italy, 2010.

30. Ltzen, J. Joseph Liouville 1809-1882, Master of Pure and Applied Mathematics; Springer-Verlag New-York, Inc.: New York, 1990. 
31. Taleb, N.N. The Fourth Quadrant: a Map of the Limits of Statistics; 2014. http://edge.org/conversation/the-fourth-quadrant-a-map-of-the-limits-of-statistics (accessed on October 10th, 2014).

32. McManus, H.; Hastings, D. A Framework for Understanding Uncertainty and its Mitigation and Exploitation in Complex Systems. IEEE Engineering Management Review 2006, Volume 34, 3, 81 pages.

33. Morris E. The Certainty of Donald Rumsfeld. The New York Times; March 25, 2014. http://opinionator.blogs.nytimes.com/tag/the-certainty-of-donald-rumsfeld/ (accessed on October $\left.10^{\text {th }}, 2014\right)$.

34. Rumsfeld D. Known and Unknown: A Memoir; Penguin: New York, 2011.

35. Roese N. Counterfactual thinking. Psychological Bulletin 1997, Volume 121, 1, 133-148.

36. Taleb, N.N. Fooled by Randomness: The Hidden Role of Chance in Life and in the Markets, 2 Updated edition; Random House Trade Paperbacks: New York, NY; August 23, 2005.

37. Hanks, T.C.; Cornell, C.A. Probabilistic Seismic Hazard Analysis: A Beginner's Guide. Proceedings of the Fifth Symposium on Current Issues Related to Nuclear Power Plant Structures, Equipment and Piping; N.C.: North Carolina State University: Raleigh; 1994; I/1-1 to I/1-17.

38. Lane,D.A.; Maxfield R.R. Ontological Uncertainty and Innovation. J. Evol. Econ. 2005, 15, 3-50.

39. Taleb, N.N.; Goldstein, D.G. The problem is beyond psychology: The real world is more random than regression analyses. International Journal of Forecasting 2012, Volume 28, 3, 715-716.

40. Goleman, D.J. Emotional Intelligence: Why It Can Matter More Than IQ; Bantam Books: New York, 1995.

41. Bateson, G. Men are Grass: Metaphor and the World of Mental Process. In A Sacred Unity: further steps to an ecology of mind; C. \& M. Bessie (eds.); A Cornelia and Michael Bessie Book: New York, 1991; pp. 235-242.

42. Blackwell, A. Thinking with diagrams; Kluwer Academic Publishers: Dordrecht, 2001.

43. Indurkhya, B. Emergent representations, interaction theory, and the cognitive force of metaphor. New Ideas in Psychology 2006, 24,133-162.

44. Collins, A. M.; Quillian, M.R. Retrieval Time From Semantic Memory. Journal of Ver-bal Behavior and Verbal Learning 1969, 8, 240-247.

45. Cheng, P.; Holyoak K. Pragmatic reasoning schemas. Cognitive Psychology 1985, 17, 391-416.

46. Gigerenzer, G. Adaptive thinking: rationality in the real world; Oxford University Press: Oxford, 2000.

47. Denis, M. Les images mentales; Presses Universitaires de France: Paris, 1979.

48. d'Aquili, E.; Newberg, .B. The Mystical Mind: Probing the biology of Religious Experience; Fortress Press: Minneapolis, 1999.

49. Tulving, E. Episodic Memory and Autonoesis: Uniquely Human? In The Missing Link in Cognition: Origins of Self-Reflective Consciousness; Terrace, O.; Metcalfe, R. Eds.; Oxford University Press: Oxford, 2005; pp. 3-56.

50. Matte Blanco, I. Unconscious as Infinite Sets: An Essay on Bilogic; Karmac: London, 1975.

51. Damasio, A.R. Stepping into the Light; Harcourt Brace: New York, 1999. 
52. Damasio, A.; Meyer, K. Consciousness: An Overview of the Phenomenon and of Its Possible Neural Basis. In The Neurology of Consciousness; Laureys, S.; Tononi, G., Eds.; Elsevier: Amsterdam, 2009; pp.3-14.

53. Morgan, J.; Tian, G., Ricci Flow and the Poincaré Conjecture; Clay Mathematics Monographs; American Mathematical Society Publications: Providence, Rhode Island, 2007; Volume 3.

54. Hadamard, J. The Psychology of Invention in the Mathematical Field, edition 1949; Dover Publications: New York, USA, 1944.

55. Poincaré, H. Mathematical Creation. Resonance, February 2000, 85-94.

56. Dirac, P.A.M. Pretty Mathematics. In International Journal of Theoretical Physics 1982, Volume 21, 603-605.

57. Stakhov, A. Dirac's Principle of Mathematical Beauty, Mathematics of Harmony and "Golden" Scientific Revolution. VI S M A T H, Electronic journal 2009, Volume 11, 1; Slavik J.; Radovic, L., Eds.; Mathematical Institute: Belgrade. http://www.mi.sanu.ac.rs/vismath/stakhov2009/mathharm.pdf (accessed on October, 10, 2014).

58. Ageno, M. Le radiazioni e i loro effetti; Paolo Boringhieri Editore: Torino, 1962.

59. Cooper, P. Unconscious Process: Zen and Psychoanalytic Versions. Journal of Religion and Health 2000, Volume 39, 1,60-61.

60. LeDoux, J.; Iwata, J.; Cicchetti, P.; Reis, D.J. Different projections of the central amygdaloid nucleus mediate autonomic and behavioral correlates of conditioned fear. The Journal of Neuroscience 1988, Volume 8, 7, 2517-2529.

61. LeDoux, J.E. Emotion Circuits in the Brain. Annual Review of Neoroscience 2000, Volume 23, 155-183.

62. LeDoux, J.E. Synaptic Self: How Our Brains Become Who We Are; Penguin Putnam: New York, 2003.

63. Eysenck, M. Psychology: An International Perspective; Taylor \& Francis: UK, 2004.

64. Shah, A.; Jhawar, S. S.; Goel, A. Analysis of the anatomy of the Papez circuit and adjoining limbic system by fiber dissection techniques. Journal of Clinical Neuroscience 2012, Volume 19, 2, 289298.

65. Newman, J.D.; Harris J.C. The scientific contributions of Paul D. MacLean (1913-2007). J. Nerv. Ment. Dis. (United States) Jan 2009, Volume 197, 1, 3-5.

66. Chopra, D.; Tanzi, R.E. Super Brain: Unleashing the Explosive Power of Your Mind to Maximize Health, Happiness, and Spiritual Well-Being; Harmony Books, Random House: New York, 2012.

67. O'Keefe, J.; Nadel, L. The Hippocampus as a cognitive map; Clarendon Press: Oxford, 1978.

68. Dorfles, G. Horror Pleni; Alberto Castevecchi Editore: Roma, 2008.

69. Shannon, C.E. A Mathematical Theory of Communication. Bell System Technical Journal July/October 1948, Volume 27, 3, 379-423.

70. Billingsley, P. Probability and Measure; Wiley: New York, 1995.

71. Fiorini, R.A. Strumentazione Biomedica: Sistemi di Supporto Attivo; CUSL Collana Scientifica: Milano, Italy, 1994.

72. Park, J.; Johnson, J.T.; Majurec, N.; Niamsuwan, N.; Piepmeier, J.R.; Mohammed, P.N.; Ruf, C.S.; Misra, S.; Yueh, S.H.; Dinardo, S.J. Airborne L-Band Radio Frequency Interference Observations From the 
SMAPVEX08 Campaign and Associated Flights. IEEE Trans. on Geoscience and Remote Sensing 2011, Volume 49, 12, 3359-3370.

73. C. E. U. European Laboratory for Particle Physics, Conseil Européen pour la Recherche Nuclaire. http://home.web.cern.ch/about/updates/2013/11/atlas-sees-higgs-boson-decay-fermions (accessed on $10^{\text {th }}$ October, 2014).

74. Halliday, M.A.K.; Webster, J. On Language and Linguistics; Continuum International Publishing Group: New York, 2006.

75. Crystal, D. Linguistics; Penguin Books: New York, 1990.

76. Martinet, A. Elements of General Linguistics; Tr. Elisabeth Palmer Rubbert (Studies in General Linguistics, vol. i.);. Faber: London, 1960; p. 15.

77. Vasu, S.C., (Tr.) The Ashtadhyayi of Panini, (2 Vols.); Benares: Uttar Pradesh, 1896.

78. Hockett, C. A Course in Modern Linguistics; Macmillan: New York, 1958.

79. Hockett, C. The Origin of Speech. Scientific American 1960, No.203, 89-96.

80. Manovich, L. The Language of New Media; MIT Press: Cambridge, 2001.

81. Hjelmslev, L. Prolegomena to a Theory of Language, (trans. Francis J. Whitfield); Univ. of Wisconsin: Madison, 1961.

82. Chomsky, A.N. Syntactic structures; Mouton: TheHague/Paris, 1957.

83. Lashley, K.S. The problem of serial order in behaviour. In Cerebral mechanisms in behaviour, The Hixon symposium; L.A. Jeffress, Ed.; Wiley: New York, 1951

84. Chomsky, N.; Schützenberger, M.P. The algebraic theory of context-free languages. In Computer Programming and Formal Systems, 1963; P. Braffort and D. Hirschbert (Eds.); North Holland: Amsterdam, 1963; pp.118-161.

85. Littlejohn,S.W.; Foss, K.A., Eds. The Encyclopedia of Communication Theory. Nonverbal Communication Theories; SAGE: Los Angeles, 2009; pp.690-694.

86. Eco, U. A Theory of Semiotics; Macmillan: London, 1976.

87. Stam, R. Film Theory; Blackwell: Oxford, 2000.

88. Craighead, W.E.; Nemeroff, C.B., Eds. The Concise Corsini Encyclopedia of Psychology and Behavioral Science, Nonverbal Communication, 3rd Edition; Wiley: New York, May 2004.

89. Paradise, R. Interactional Style and Nonverbal Meaning: Mazahua Children Learning How to Be Separate-But-Together. Anthropology \& Education Quarterly1994, Volume 25, 2, 156-172.

90. Hogan, K.; Stubbs, R. Can't get Through 8 Barriers to Communication; Pelican Publishing Company: Grenta, LA, 2003.

91. Demarais,A.; White, V. First Impressions; Bantam Books: New York, 2004.

92. Pease B.; Pease A. The Definitive Book of Body Language; Bantam Books: New York, 2004.

93. Manovich, L. Software Takes Command; Bloomsbury Academic, New York, 2013.

94. Umpleby, S.; Chandler, J.; Leonard, A.; Lissack, M.; Loeckenhoff, H., Medvedeva, T., Solomons, L. Science II: A Report from the 2012 IFSR Conversation, 2012. http://www.gwu.edu/ umpleby/recent.html (accessed on October 10th, 2014).

95. Lefebvre, V. Algebra of Conscience: A Comparative Analysis of Western and Soviet Ethical Systems; Reidel: Boston, MA, 1982.

96. Soros, G. The Alchemy of Finance: Reading the Mind of the Market; Wiley: Chichester, UK, 1987. 
97. Von Foerster, H.; Poerksen, B. Understanding Systems: Conversations on Epistemology and Ethics; Kluwer: New York, NY, 2002.

98. Nicolescu, B., Ed. Transdisciplinarity - Theory and Practice; Hampton Press: Cresskill, New Jersey, 2008.

99. Stein, J., Ed. The Random House Dictionary of the English Language; Random House: New York, 1968.

100. Umpleby, S. Reflexivity in Social Systems: The Theories of George Soros. Systems Research and Behavioral Science 2007, 24, 515-522.

101. Coxeter, H.S.M. Introduction to Geometry, 2nd ed.; John Wiley \& Sons: New York, NY, 1969.

102. Lieberman, M.C. Reflexive and Reflective Judgment Processes: A Social Cognitive Neuroscience Approach. In Social Judgments: Implicit and Explicit Processes; Forgas, J.P.; Williams, K.D.; Von Hippel, W., Eds.; Cambridge University Press: Cambridge, 2003; pp.3-67.

103. Bruner, J. S. On perceptual readiness. Psychological Review 1957, 64, 123-152.

104. Haidt, J. The emotional dog and its rational tail: A social intuitionist approach to moral judgment. Psychological Review 2001, 108, 814-834.

105. Hogarth, R. H. Educating intuition; University of Chicago Press: Chicago, 2001.

106. Lieberman, M.D. Intuition: A social cognitive neuroscience approach. Psychological Bulletin 2000, 126, 109-137.

107. McClelland, J.L.; McNaughton, B.L.; O’Reilly, R.C. Why there are complimentary learning systems in the hippocampus and neocortex: insights from the successes and failures of connectionist models of learning and memory. Psychological Review 1995, 102, 419-457.

108. Jaspers, K.T. Psychologie der Weltanschauungen; Springer: Berlin, 1919.

109. Jaspers, K.T. Existenzphilosophie; Berlin: de Gruyter: Berlin, 1938. (Translated as, Philosophy of Existence, trans. R. F. Grabau, Philadelphia: University of Pennsylvania Press, 1971).

110. Jaspers, K.T. Einführung in die Philosophie; Zurich: Artemis: Zurich, 1950. (Translated as, Way to Wisdom: An Introduction to Philosophy, trans. R. Manheim, New Haven: Yale University Press, 1951).

111. Jaspers, K.T. Vernunft und Widervernunft in unserer Zeit; Piper: Munich, 1950. (Translated as, Reason and Anti-Reason in our Time, trans. S. Goodman, New Haven: Yale University Press, 1952).

112. Wittgenstein, L. Tractatus Logic-Philosophicus; Keagan Paul: New York, 1922.

113. Pólya, G. Sur les types des propositions composées. Journal of Symbolic Logic 1940, 5, 98-103.

114. Givant, S.R.; McKenzie, R. N., Eds. The Collected Papers of Alfred Tarski, 4 vols; Birkauser: Berlin, 1986.

115. Cohen, P.J. Set theory and the continuum hypothesis; Addison-Wesley: Boston, 1966.

116. Troelstra, A.S. Ed. Metamathematical investigation of intuitionistic arithmetic and analysis; Springer: Berlin, 1973.

117. Kripke, S.A. Semantical analysis of intuitionistic logic I. In Formal Systems and Recursive Functions; Crossley, J.N.; Dummett, M.A.E., Eds.; North-Holland: Amsterdam, 1965; pp. 92130. 
118. Statman, R. Intuitionistic propositional logic is polynomial-space complete. Theoretical Comput. Sci. 1979, 9, 67-72.

119. Cook, S.A. (1971). The complexity of theorem proving procedures. In: Proc. 3rd Annual ACM Symp. on the Theory of Computing; ACM: NewYork, 1971; pp. 151-158.

120. Grzegorczyk, A. Undecidability of some topological theories. Fundamenta Mathematicae 1951, 38:137-152.

121. Johnstone, P.T. Stone Spaces; Cambridge University Press: Cambridge, 1982.

122. Kusraev, A.G.; Kutateladze, S.S. Boolean valued analysis; Springer: Berlin, 1999.

123. Demey, L.; Smessaert, H., The relationship between Aristotelian and Hasse Diagrams. Diagrammatic Representation and Inference 2014, 8578, 213-227.

124. Moretti, A. The Geometry of Logical Opposition. Ph.D. thesis, Univ. of Neuchâtel, Switzerland, 2009.

125. Judson, T. Abstract Algebra: Theory and Applications. GNU Free License Document, 7th edition, 2013. http://abstract.pugetsound.edu (accessed on October $10^{\text {th }}, 2014$ ).

126. Johnson-Laird, P.N. Mental models and deduction. Trends in Cognitive Science 2001, 10, 434442.

127. Morineau, T. Hypercube algebra: a diagrammatic and sentential notation to support inferences in logic. In Proc. 30th European Conf. on Cognitive Ergonomics, ECCE '12, 2012; pp. 100-104.

128. Eshach, H.; Bitterman, H. From case-based reasoning to problem-based learning. Academic Medicine 2003, 78,491-496.

129. Chang, G.; Weiss, A.P.; Orav, E.J.Bottlenecks in the emergency department: the psychiatric clinicians' perspective. General Hospital Psychiatry 2012, 34,403-409.

130. Hillard, R.; Zitek, B. Emergency Psychiatry; McGraw-Hill: New York, 2004.

131. Høglend, P. Exploration of the Patient-Therapist Relationship in Psychotherapy. Am. J. Psychiatry Jul 14 2014. doi: 10.1176/appi.ajp.2014.14010121. [Epub ahead of print]

132. Rouse, W.B. Human problem solving performance in a fault diagnosis task. IEEE Transactions on Systems, Man, and Cybernetics 1978, SMC-8, 258-271.

133. Sanderson, P.M.; Murtagh, J.M. Troubleshooting with an inaccurate mental model. In Proc. IEEE International Conference on Systems, Man, and Cybernetics, 1989; pp.1238-1243.

(C) 2014 by the authors; licensee MDPI, Basel, Switzerland. This article is an open access article distributed under the terms and conditions of the Creative Commons Attribution license (http://creativecommons.org/licenses/by/3.0/). 